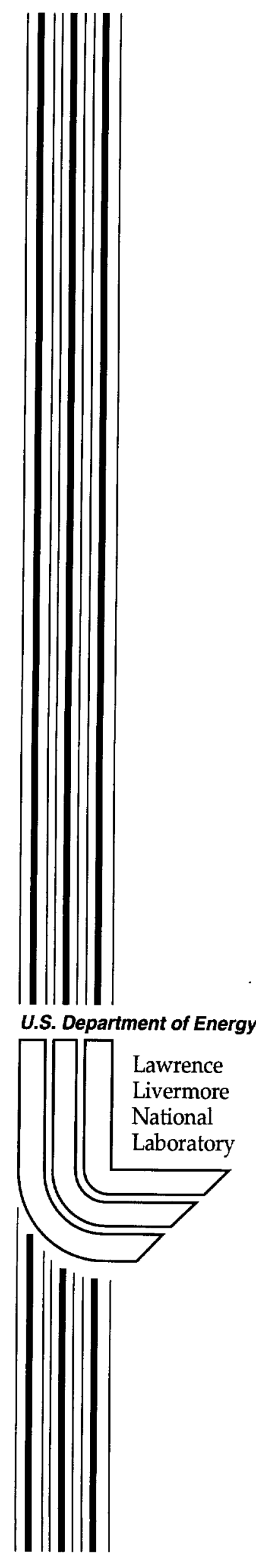

UCRL-ID-142551

\title{
High-Speed, Three- Dimensional Object Composition Mapping Technology
}

P. Armstrong, M. Ishikawa, B. Stuart, L. Wood, A. Wynne

February 14, 2001 


\section{DISCLAIMER}

This document was prepared as an account of work sponsored by an agency of the United States Government. Neither the United States Government nor the University of California nor any of their employees, makes any warranty, express or implied, or assumes any legal liability or responsibility for the accuracy, completeness, or usefulness of any information, apparatus, product, or process disclosed, or represents that its use would not infringe privately owned rights. Reference herein to any specific commercial product, process, or service by trade name, trademark, manufacturer, or otherwise, does not necessarily constitute or imply its endorsement, recommendation, or favoring by the United States Government or the University of California. The views and opinions of authors expressed herein do not necessarily state or reflect those of the United States Government or the University of California, and shall not be used for advertising or product endorsement purposes.

This work was performed under the auspices of the U. S. Department of Energy by the University of California, Lawrence Livermore National Laboratory under Contract No. W-7405-Eng-48.

This report has been reproduced directly from the best available copy.

Available electronically at http://www.doe.gov/bridge

Available for a processing fee to U.S. Department of Energy

and its contractors in paper from

U.S. Department of Energy

Office of Scientific and Technical Information

P.O. Box 62

Oak Ridge, TN 37831-0062

Telephone: (865) 576-8401

Facsimile: (865) 576-5728

E-mail: reports@adonis.osti.gov

Available for the sale to the public from

U.S. Department of Commerce

National Technical Information Service

5285 Port Royal Road

Springfield, VA 22161

Telephone: (800) 553-6847

Facsimile: (703) 605-6900

E-mail: orders@ntis.fedworld.gov

Online ordering: http://www.ntis.gov/ordering.htm

OR

Lawrence Livermore National Laboratory

Technical Information Department's Digital Library

http://www.llnl.gov/tid/Library.html 


\section{R\&D 100 Award Entry}

\section{High-Speed, Three-Dimensional \\ Object Composition Mapping Technology}

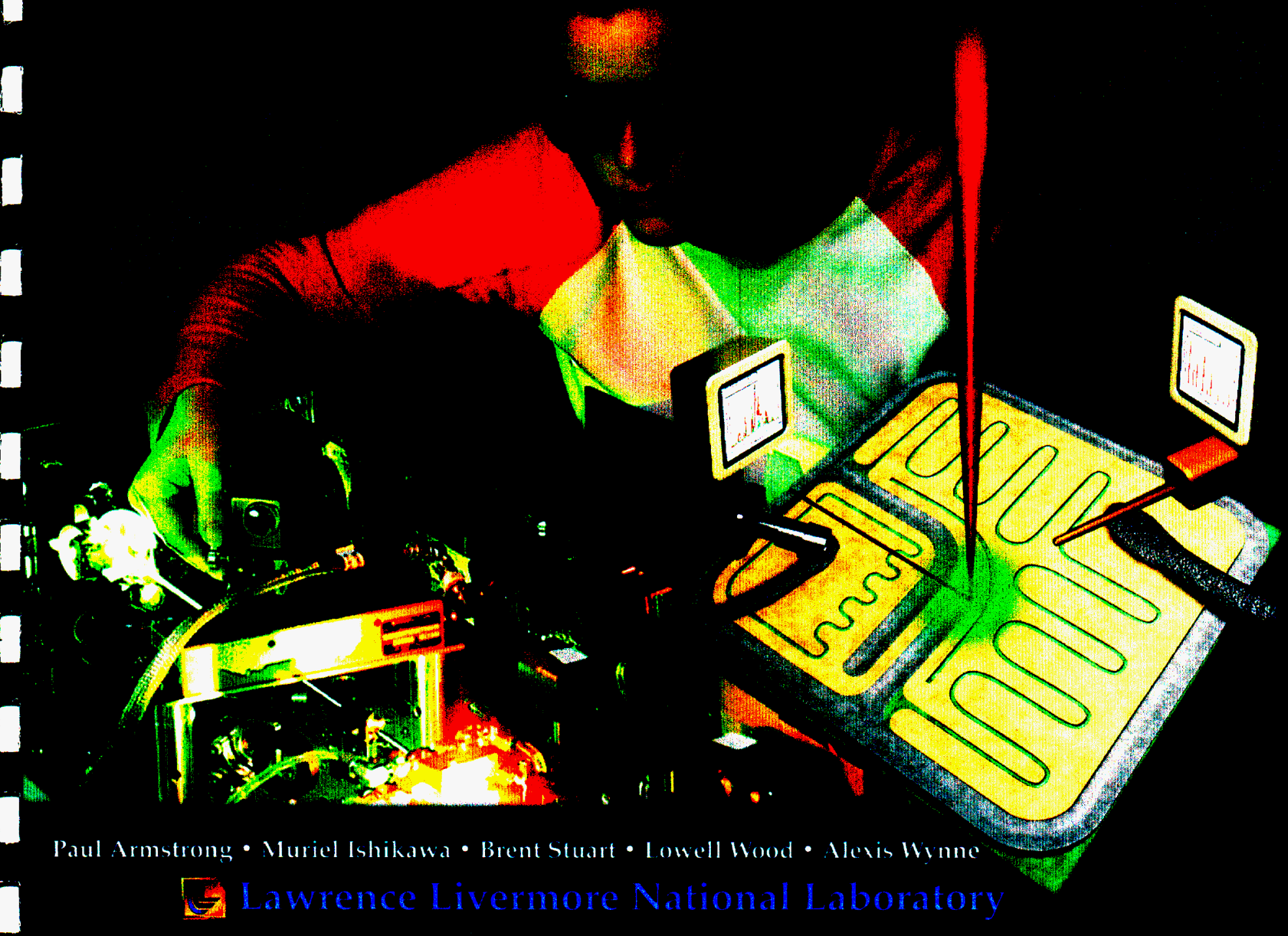




\begin{abstract}
This document overviews an entirely new approach to determining the composition - the chemical-elemental, isotopic and molecular make-up - of complex, highly structured objects, moreover with microscopic spatial resolution in all 3 dimensions.

The front cover depicts the new type of pulsed laser system at the heart of this novel technology under adjustment by Alexis Wynne, and schematically indicates two of its early uses: swiftly analyzing the 3-D composition governed structure of a transistor circuit with both optical and mass-spectrometric detectors, and of fossilized dinosaur and turtle bones high-speed probed by optical detection means.

Studying the composition-cued 3-D micro-structures of advanced composite materials and the microscopic scale composition-texture of biological tissues are two near-term examples of the rich spectrum of novel applications enabled by this fieldopening analytic tool-set.
\end{abstract}

This work was performed under the auspices of the U.S. Department of Energy by the University of California

Lawrence Livermore National Laboratory under contract No. W-7405-ENG-48. 


\section{R\&D 100 AWARDS ENTRY FORM}

\section{Submitting Organization}

\begin{tabular}{|c|c|}
\hline $\begin{array}{r}\text { Organization } \\
\text { Name }\end{array}$ & Lawrence Livermore National Laboratory \\
\hline Address & P.O. Box 808, L-278 \\
\hline Address & 7000 East Avenue \\
\hline City & Livermore \\
\hline State & California \\
\hline Zip & 94551 \\
\hline Country & USA \\
\hline $\begin{array}{r}\text { Submitter's } \\
\text { Name }\end{array}$ & Muriel Y. Ishikawa \\
\hline Phone & $(925) 423-4178$ \\
\hline Fax & $(925) 423-1243$ \\
\hline Email & ishikawa1@llnl.gov \\
\hline
\end{tabular}

AFFIRMATION: I affirm that all information submitted as a part of, or supplemental to, this entry is a fair and accurate representation of this product.

Submitter's signature

Myurel

y.

\section{Joint entry}

N/A

\section{Product name}

High-Speed, Three-Dimensional Object Composition-Mapping Technology (DOCMT)

4. Briefly describe ( 25 words or less) what the entry is (e.g. balance, camera, nuclear assay, etc.)

A technology for ultrahigh-spatial resolution mapping of the isotopic, molecular, and chemical compositions of complex, multi-dimensional objects, in semiconductor, paleontological, archaeological, biological and materials R\&D. 
5. When was this product first marketed or available for order? Proof of actual sale or intent to sell must be submitted (i.e. invoice, marketing brochure, a one-page letter from a company using your product). (Must have been first available in 2000.)

Month: Commerce Business Daily, June 2000

An early form of the present technology (CASFLU, or Composition Analysis by Scanned Femtosecond Laser Ultraprobing) was submitted to the 1999 R\&D 100 competition. Major improvements were made in 2000 and motivate the present submission. These include full automation of 3-D analytic capabilities: simultaneous multi-element analysis and composition-mapping; computerized semi-automatic generation of material composition maps; and demonstration of full-scale semiconductor device dissection and composition-mapping which is of immediate interest to the advanced semiconductor R\&D and manufacturing communities. These advances have greatly extended the demonstrated domain-of-capabilities of the present technology and have thereby increased substantially its attractiveness to potential customer communities.

\section{Inventor or Principal Developer}

(List additional developers from all companies on a separate sheet in an appendix and check here $\sqrt{ }$,

\begin{tabular}{|} 
Developer Name Muriel Y. Ishikawa \\
Position Physicist \\
Organization Lawrence Livermore National Laboratory \\
Address P.O Box 808, L-278 \\
Address 7000 East Avenue \\
City Livermore \\
State California \\
Zip 94551 \\
Country USA \\
Phone (925) 423-4178 \\
Fax (925) 423-1243
\end{tabular}

\section{Product price}

(If the price is proprietary, fill in the blank and also check here $\Gamma$ ).

Price depends on how the technology is packaged. There are very many possible packagings, depending primarily on the desired speed of composition mapping and on the number and sensitivities of the analysis and mapping stations (e.g., the chemical-elemental, isotopic and molecular detector heads). The underlying technology is being offered for licensing to analytic equipment manufacturers serving various fields, as well as in its already demonstrated formats for vendor 
customization and mass production. It is anticipated that vendors will initially price the already demonstrated equipment at \$75-125 K, depending on compositionmapping speed (which determines the size of the femtosecond laser, which in turn drives the overall system cost in most formats). Mass production costs for middleof-the-market systems are expected to drop swiftly into the \$10-20 K range with increasing production volumes. In all cases, however, sales prices will be determined entirely by vendor/licensees.

8. Do you hold any patents or patents pending on this product?

Yes

No $r$ 


\section{Describe your product's primary function as clearly as possible in one page. What does it do? How does it do it? What theories, if any, are involved?}

What does it do? This is a fully automated, high-speed technology useful for mapping the spatially-varying material composition of an object. It can be used for the chemical, molecular and isotopic composition analysis of complex, three-dimensional objects of any nature, and its spatial resolution is at the microscopic (potentially submicrometer) level.

This composition mapping technology integrates a femtosecond laser, an optical and/or mass spectrometer, and a control computer into a powerful tool used to determine the material make-up of objects of all types, shapes, and compositions. Near-term applications are in the semiconductor industry, in materials, medical, paleontological and archaeological research, and in national security task-areas.

How does it do it? Because the laser pulses used are extremely short in duration ( $\leq 100$ femtoseconds, or $10^{-13}$ seconds), they can remove a very thin (submicrometer) surface layer of an object without heating or shocking underlying material-the object's uppermost layer is heated to $>10,000$ kelvins in a tenth of a trillionth of a second. The superheated, completely gasified material 'gently' lifts off on a sub-nanosecond time scale. What remains is an unheated, unshocked, flat surface that looks precisely micro-machined, and is suitable for subsequent analysis.

Composition Analysis. The tiny parcel of material ablated by each focused laser beam pulse may be analyzed in real time by spectrometers for chemical, isotopic, and molecular compositions; the entire object is analyzed by sweeping trains of these pulses across the object's exposed surface, repetitively. (The object surface being analyzed is typically shrouded by flowing inert gas; the mass spectrometer's inlet sees only the inert gas except when exposed to the vapor from the pulseablated material, which is uncontaminated with vapor-air reaction products). The chemical composition of ablated material is determined by optical spectrometry, which examines the electronic spectral signature briefly emitted by each tiny parcel of the vaporized material. This sampling-analysis cycle may be made to occur millions of times per second, and may be repeated indefinitely, under computer control. The entire surface of the object being analyzed is precision-scanned under the focal spot of the laser beam to generate a two-dimensional composition map of its presented surface. This two-dimensional analysis is iterated, layer-by-layer, to build up a microscopically precise three-dimensional map of the object's composition.

What theories, if any, are involved? The energy of pulsed laser irradiation is absorbed by the electrons in the topmost layers of a material and is thermally conducted by them and subsequently by the material's intermingled atoms and ions, as the hot electrons couple thermal energy into them. For laser pulses of durations that are short compared to the material's electron-ion thermal coupling time (about 1 picosecond), the very high pressure of the superheated electron 'gas' by itself causes the associated 'cold' material to explosively lift off in a layer that is only a few electron scattering-lengths in depth. Since the $>99.9 \%$ of the mass of the vaporized material represented in atoms and ions never gets hot, the underlying surface isn't significantly heated or otherwise damaged. This phenomenon is necessarily limited to femtosecond-pulse irradiation and results in a novel type of material machining offered by the very high spatial resolution of focused laser light. 


\section{A. List your product's competitors by manufacturer, brand name and model number.}

There are no known products in the general performance class of this technology. All previous composition-mapping technologies are severely limited by their spatial resolution, composition range, or size or shape of analyzable objects. The comparative performance shortfalls are qualitative ones. Nothing else can micro-dissect an object of arbitrary composition in 2- or 3-D, and composition-analyze the dissected masspackets with any significant generality of chemical and/or isotopic composition or high speed or automation, moreover in a 'seamless' manner.

A unique application of the High-Speed 3-D Object Composition Mapping Technology derives from its ability to determine an object's local composition in real time. Leveraging this capability, systems expressing this technology can extract (potentially microscopic) "daughter" objects embedded within a "parent" object. The system's laser can suspend ablation on low-latency time scales when the control computer detects either a pre-designated or unknown material via interpretation of signals from a detector head, while continuing to swiftly ablate micro-parcels more distantly from this 'preferred' material. The embedded or "daughter" object can thereby be rapidly and automatically 'carved out' of its surrounding matrix, moreover with microscopic precision. There is no known technology that can perform such extractions with any generality. This capability is of particular interest to the paleontological and archaeological communities, as well as to the biological micro-anatomy one. 
10B. Supply a matrix or table showing how the key features of your product compare to existing products or technologies. Include both numerical (data) and descriptive (written) comparisons.

The present technology broadly and directly benefits the overall high-technology sectors of the economy by providing a first-of-its-kind tool for automatically and precisely disassembling and composition-analyzing complex, three-dimensional objects and doing so at very high speed and without human contact with the objects as they're being analyzed.

The ability to "look" at objects on single-micrometer spatial scales is comparable to that of the best optical microscopes (which, indeed, are employed to focus the ultra-short pulses of laser light). However, the ability to thereupon analyze the molecular, chemical-elemental and isotopic compositions of the volumes examined on these same microscopic resolution scales, all over an area which is potentially dozens to hundreds of square centimeters in extent, is completely unprecedented and is of great significance to advanced understanding of both the micro-structure and the utility of materials of all types. The ability to then "push" the surface being so examined all the way through the entire object in fractional micrometer steps while maintaining microscopic spatial resolution in the two transverse dimensions is also quite novel, and can be expected to lead to greatly improved understanding of many aspects of advanced and highly-structured materials, e.g., high-strength composites and 3-D composition and connectivity of biological tissues.

The following table compares generally competitive technologies versus implementation; spatial resolution; chemical, isotopic and molecular identification capabilities; and cost and applicability. 
Technologies

\begin{tabular}{|c|c|c|c|c|}
\hline Characteristics & $\begin{array}{l}\text { X-Ray } \\
\text { Tomography }\end{array}$ & $\begin{array}{l}\text { Magnetic } \\
\text { Resonance } \\
\text { Imaging }\end{array}$ & $\begin{array}{l}\text { Stacks-of-Planar } \\
\text { Slabs Analysis }\end{array}$ & DOCMT \\
\hline Implementation & $\begin{array}{l}\text { "CAT scan" } \\
\text { imagery }\end{array}$ & MRI imagery & $\begin{array}{l}\text { Microtome-to- } \\
\text { slide-to-optical } \\
\text { microscope } \\
\text { imaging }\end{array}$ & $\begin{array}{l}\text { Scanned- } \\
\text { dissection } \\
\text { whole-object } \\
\text { analysis }\end{array}$ \\
\hline $\begin{array}{l}\text { Spatial } \\
\text { resolution: } \\
\text { Transverse Depth }\end{array}$ & $\begin{array}{l}\sim 0.05 \mathrm{~cm} \\
\sim 0.05 \mathrm{~cm}\end{array}$ & $\begin{array}{l}\sim 0.05 \mathrm{~cm} \\
\sim 0.1 \mathrm{~cm}\end{array}$ & $\begin{array}{l}\sim 0.0001 \mathrm{~cm} \\
\sim 0.001 \mathrm{~cm}\end{array}$ & $\begin{array}{l}\sim 0.0001 \mathrm{~cm} \\
\sim 0.00001 \mathrm{~cm}\end{array}$ \\
\hline $\begin{array}{l}\text { Chemical-element } \\
\text { resolution }\end{array}$ & $\begin{array}{l}\text { Crude; } \\
\text { specialized }\end{array}$ & $\begin{array}{l}\text { Nearly non- } \\
\text { existent }\end{array}$ & $\begin{array}{l}\text { Elemental stains } \\
\text { only }\end{array}$ & All elements \\
\hline $\begin{array}{l}\text { Isotopic resolution } \\
\text { capabilities }\end{array}$ & None & Very few & None & All isotopes \\
\hline $\begin{array}{l}\text { Molecular } \\
\text { identification } \\
\text { capabilities }\end{array}$ & None & $\begin{array}{l}\text { Contrast } \\
\text { agents only }\end{array}$ & $\begin{array}{l}\text { Stained entities } \\
\text { only }\end{array}$ & $\begin{array}{l}\text { Full mass- } \\
\text { spectrometer } \\
\text { capabilities }\end{array}$ \\
\hline Cost & High & High & Low & Moderate \\
\hline Applicability & $\begin{array}{l}\text { Low-Z or } \\
\text { small objects } \\
\text { only }\end{array}$ & $\begin{array}{l}\text { Non-magnetic, } \\
\text { RF-transparent } \\
\text { objects only }\end{array}$ & $\begin{array}{l}\text { Thin sectioning- } \\
\text { tolerant, optically } \\
\text { transparent }\end{array}$ & $\begin{array}{l}\text { All materials } \\
\text { and all object- } \\
\text { sizes }\end{array}$ \\
\hline
\end{tabular}


10C. Describe how your product improves upon competitive products or technologies. BE SPECIFIC! Include such items as how much faster, how much less cost, etc.

This second table displays the comparative applicability of existing analytic technologies in terms of applications to semiconductor device failure analysis, mechanical wear and failure analysis, object construction and biological tissue assay.

Comparative Applicability of Analytic Technologies

\begin{tabular}{|l|l|l|l|l|}
\hline $\begin{array}{l}\text { Representative } \\
\text { Applications } \\
\text { Classes }\end{array}$ & $\begin{array}{l}\text { X-Ray } \\
\text { Tomographic } \\
\text { (CAT-Scan) } \\
\text { Imaging }\end{array}$ & $\begin{array}{l}\text { Magnetic } \\
\text { Resonance } \\
\text { Imaging }\end{array}$ & $\begin{array}{l}\text { Microtome- } \\
\text { Optical } \\
\text { Microscope } \\
\text { Imaging }\end{array}$ & DOCMT \\
\hline $\begin{array}{l}\text { Semiconductor } \\
\text { device failure } \\
\text { analysis }\end{array}$ & $\begin{array}{l}\text { None (very } \\
\text { poor resolution; } \\
\text { no chem.) }\end{array}$ & $\begin{array}{l}\text { None (very poor } \\
\text { resolution; no } \\
\text { chem.) }\end{array}$ & $\begin{array}{l}\text { Minimal (inadequate } \\
\text { resolution; limited } \\
\text { chem.; no penetration) }\end{array}$ & Full \\
\hline $\begin{array}{l}\text { Mechanism } \\
\text { wear/failure } \\
\text { analysis }\end{array}$ & $\begin{array}{l}\text { None (poor } \\
\text { resolution; limited } \\
\text { penetration) }\end{array}$ & $\begin{array}{l}\text { None (poor } \\
\text { resolution; very } \\
\text { limited penetration) }\end{array}$ & $\begin{array}{l}\text { None (very limited } \\
\text { penetration; limited } \\
\text { chem./molecular) }\end{array}$ & Full \\
\hline $\begin{array}{l}\text { Object } \\
\text { construction } \\
\text { analysis }\end{array}$ & $\begin{array}{l}\text { Minimal (poor } \\
\text { resolution; no } \\
\text { penetration) }\end{array}$ & $\begin{array}{l}\text { None (poor } \\
\text { resolution; no } \\
\text { chem./molecular; } \\
\text { very limited } \\
\text { penetration) }\end{array}$ & $\begin{array}{l}\text { None (very limited } \\
\text { penetration; limited } \\
\text { chem./molecular) }\end{array}$ & Full \\
\hline $\begin{array}{l}\text { Biological tissue } \\
\text { analysis }\end{array}$ & $\begin{array}{l}\text { Minimal (poor } \\
\text { resolution; no } \\
\text { chemical or } \\
\text { molecular) }\end{array}$ & $\begin{array}{l}\text { Minimal (poor } \\
\text { resolution; very } \\
\text { limited chemical or } \\
\text { molecular) }\end{array}$ & $\begin{array}{l}\text { Marginal (limited } \\
\text { penetration; very } \\
\text { limited/stylized } \\
\text { chem./molecular \& no } \\
\text { isotopic) }\end{array}$ \\
\hline
\end{tabular}


10C. Continued.

\section{Spatial Resolution.}

- Optical microscopy has comparable transverse spatial resolution, but

- it has exceedingly limited depth resolution, and only over very small total transverse field-sizes and depths-of-field.

- it has essentially no ability to analyze chemical or isotopic composition, and its molecular composition analysis is limited to a handful of stains and fluors.

- Potentially 3-D analysis systems such as MRI and x-ray tomography - have at least a hundred-fold poorer limiting spatial resolutions in all three dimensions (i.e., a typical minimum feature-size is $>>100$ micrometers). - are very limited in the range of chemical and isotopic compositions they can assay. In general, they report appearance but not composition, form but not content.

Composition Range and Type. The present technology has all-materials analytic capabilities. In comparison,

- MRI is limited to compounds containing odd-nuclear-spin species in nonmagnetic materials.

- X-ray tomographic approaches (e.g, CAT-scan) must work with only singleelement line-edges in nearly (x-ray) transparent media.

- SIMS techniques offer no significant 2- or 3-D spatial analytic coverage, little unambiguous chemical/molecular information, and isotopic mass resolution of only intermediate quality and reliability.

Material Types. The present technology is indifferent to the type of materials being analyzed. In comparison,

- MRI works only with non-magnetic materials and essentially assays for a small number of odd-spin nuclei.

- Specialized CAT-scanning can resolve materials of just a single chemicalelemental composition.

- Optical microscopy is limited to nearly transparent materials and has no intrinsic chemical or isotopic analytic ability. Its molecular composition ability is limited to ad hoc staining with colored, fluorescent, or optically dense materials of negligible generality. 


\section{C. Continued.}

\section{Object Scales.}

- The present technology works with objects of any size or shape. Other composition-mapping technologies are limited to objects that present only a small number of optical depths to the various radiations with which they are probed, e.g., non-metallic objects. This restriction to nearly transparent objects often is severely limiting.

- The present technology uniquely combines the spatial resolution of an optical microscope with the analytic power of simultaneously applied optical- and mass-spectroscopy.

- Moreover, the present technology composition-maps objects at singularly high sampling rates: $\leq 10^{8} /$ second, thereby making practical the composition mapping of extended 2- and 3-D objects, and, moreover, with microscopic precision.

Simultaneous Multi-axis Composition-Mapping. The present technology can look simultaneously at the chemical, isotopic, and molecular compositions of an object being analyzed, moreover at very high spatial-tracking rates. All other analytic approaches look at an object only along a single axis in compositionspace, and typically do so at exceedingly modest spatial-track speeds.

- SIMS looks only at the isotope abundances at a single site on an object's surface with moderate-mass resolution.

- Optical microscopy looks only at the optical density within a thin, semitransparent section of a (possibly fluor- or stain-taking) material, in 2-D.

- Ordinary CAT-scanning looks only at total electron density, while advanced CAT techniques can examine only the density of a single chemical element.

In summary, the present technology is a qualitative advance over the best previous technologies for composition-analyzing complex 2- \& 3-D objects. 


\title{
11A. Describe the principal applications of this product.
}

\author{
Benefits to the General Public.
}

As a powerful, general-purpose means for understanding the structure of material objects - whether naturally-occurring or man-made - the present technology can be expected to come into widespread use in analytical science and engineering and thus to have large-scale beneficial consequences. Both the direct and indirect benefits to the economy can reasonably be expected to be large and varied.

\section{Applications.}

This technology broadly and directly benefits the overall high-technology sectors of the economy by providing a first-of-its-kind tool for automatically and precisely disassembling and composition-analyzing complex, three-dimensional objects at very high speed, without human contact with the objects as they are being analyzed.

The ability conferred by the present technology to examine objects on singlemicrometer spatial scales is comparable the best optical microscopes. The ability to look all the way through an entire macroscopic object in fractional micrometer steps - while maintaining microscopic spatial resolution in the two transverse dimensions may lead to greatly improved understanding of advanced and highly-structured materials, ranging from high-performance composites to biological tissues (and their medical surrogates).

Salient semiconductor applications are addressed is the accompanying video. As a generic example of the High-Speed 3-D Object Composition Mapping Technology, we raster-scanned in horizontal layers through a Darlington bipolar transistor circuit implemented in silicon-aluminum technology. The video shows the resulting multidimensional computer-analyzed result. The computer-synthesized 3-D image accentuates the minute thickness of the device, relative to its transverse extents; the four individual layers shown are separated only by a few micrometers.

This composition mapping technology is expected to be especially useful in archaeological and paleontological applications, in addition to microelectronics research. It can be used to separate an object of one composition from surrounding material of differing composition(s), for example, for the microscopically precise retrieval of paleontological and archeological objects embedded inside of closely adhering (and very similar-appearing) surrounding material. Because the composition analyses detect changes in the material in real time, the presence of an embedded object can be detected readily, and the dissection of surrounding material thereby may be guided reliably to effect the embedded object's precise removal.

Two typical applications of this high-speed composition-mapping technology are the removal of metal archeological objects from compacted soil or corrosion crusts and the separation of mineralized bone paleontological specimens from surrounding rock. 
Figure Caption. In 1999, the present technology was successfully employed to differentiate between challenging samples of "rock-in-rock". Cretaceous rock and mineralized bone fossils were compared to each other and to Jurassic rock and fossils from different parts of the U.S. The results are illustrated in this figure. Both fossil bone samples were readily distinguished from rock in which they were embedded and from fossilized contemporaneous chitinous turtle shell, using the optical spectral analytic capabilities of the present technology. In the left plot, two dinosaur fossil bone specimens from different geological times and geographical locations were found to lie on top of each other, in the optical spectral sense. The fossil chitinous turtle shell specimen clearly is differentiated readily from the fossil bone specimen in the center graph. Another plot (omitted for lack of space) showed the two fossil bone-carrying rock specimens also closely related to each other spectrally, despite formation in disparate geologic eras and locations. However, the spectroscopic analysis clearly illuminates the difference spectrally between the fossil bone and the encasing rock in the plot on the right [Cf. "Automated, High-Speed, High Resolution Specimen Recovery From Matrix With Femtosecond Laser Pulse-Trains," E.M. Campbell, M. Perry, B. Stuart, M. Ishikawa and L. Wood, J. Vertebrate Paleontology 19, A35 (1999).]

This research was done in collaboration with Dr. Kenneth Carpenter of the Denver Museum of Natural History in Denver, Colorado and Dr. James Kirkland, State Paleontologist of Utah, Salt Lake City, Utah. 


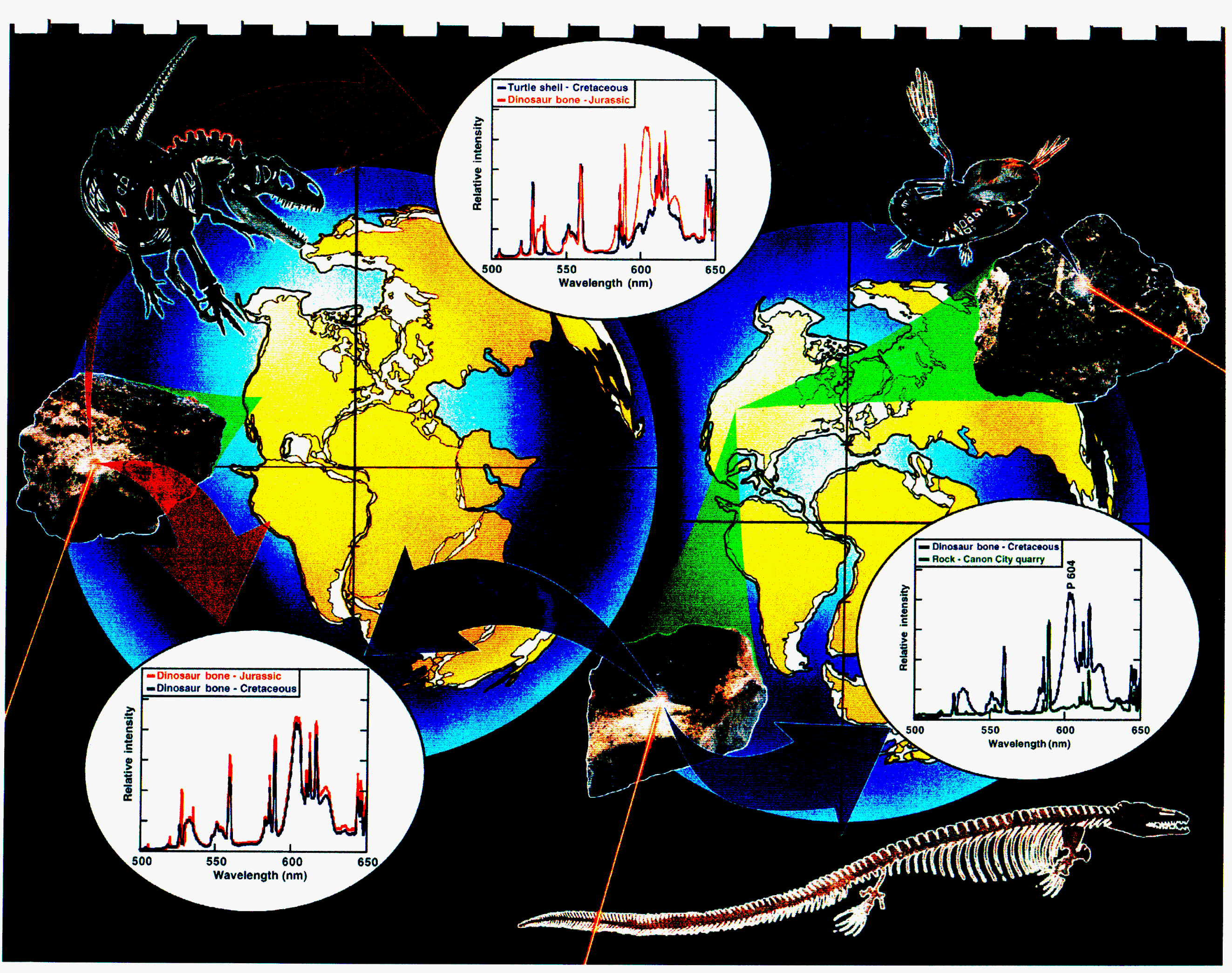




\section{B. List all other applications for which your product can now be used.}

\section{Public Sector Applications.}

The capabilities of the present technology constitute one of the single largest advances in forensic science capabilities during the past half-century: uniformly resolving an object into as many as a trillion uniform mass-parcels or -aliquots per cubic centimeter and reading-out the composition of each such parcel automatically and at very high speed.

For example, both Federal and State law-enforcement agencies can be expected to welcome the capabilities of the present technology for use in the full spectrum of forensic analytic applications. Those agencies of the government charged with responsibilities for reliably and swiftly attributing unconventional and asymmetric attacks on the armed forces, population and interests of the United States likely will also be intrigued by the unique object micro-analysis capabilities being made available by the present technology-set. Other government agencies which have (often, time-urgent) requirements for elucidating the 3-D structure and composition of (typically, small) complex objects likewise may be expected to be pleased by the capabilities of the present technology, e.g., the Environmental Protection Agency may value its ability to differentiate between contested sites-of-origin of fly ash from coal combustion via combined chemical and isotopic analyses of single ash particles.

\section{Biological Applications.}

Near-term biological applications center on the elementally guided micro-dissection of (frozen) biological tissue. Since many tissue-types have very large differences in intra- and extra-cellular concentrations of chemical elements ( $>1000$-fold calcium concentration ratios, in the case of mammalian brain tissue), the sub-micron scale mass aliquoting and composition analyses offered by the present technology may be used to create the first-ever high-resolution, seamless, fully-assembled 3-D maps of all such complex tissue structures, moreover over comparatively very large (e.g., cubic centimeter) volume scales.

The corresponding advances in areas as diverse as fundamental neuroanatomy and tissue engineering are anticipated to be quite large, as all existing microscopic imaging approaches cannot register stacks of 2-D images relative to each other in order generate deep 3-D representations of biological structures. The abilities to "see in depth" and with micrometer-scale resolution in all 3 dimensions which are conferred by the present technology may virtually revolutionize biological micro-imagery, and may reinvigorate micro-anatomy as a discipline, e.g., entire functional-level neural circuits (with $10^{5}-10^{6}$ neurons) may be imaged in their full interconnectivity for the first time.

\section{Advanced Materials Studies.}

The highest-performance structural materials are composites, usually fiber-based ones. How these materials perform under high loadings, at high temperatures, when abruptly loaded, etc. is often determined by microscopic deviations in compositional properties from the as-built material, e.g., formation of low-density or compositionallyaltered microvolumes of complex geometry at-or-near material interfaces within objects comprised of such composites. The present technology will be of exceptional utility in extending understanding of how these unusual materials perform and fail, and thus will point the way to improving them, both in formation and in conditions-of-use. Such prospects are of great interest to a wide variety of modern technologists, as is noted in the enclosed letters from Ferren and MacCready.

Semiconductor manufacturing and characterization applications are noted elsewhere. 
12. Summary. State in layman's terms why you feel your product should receive an R\&D 100 Award. Why is it important to have this product? What benefits will it provide? (The value of the award for its promotional value is understood.)

Optical microscopes extended human vision another two orders of magnitude into the small-scale world, and $x$-ray imaging enabled human "seeing" into the interiors of apparently opaque objects. Each revolutionized human perceptions of the physical world, and subsequently proved to be of enormous technological significance.

The High Speed 3-D Object Composition-Mapping Technology makes available a major imaging advance, relative to these justly-famed technology-sets.

Powerfully leveraging and integrating very recent advances in pulsed laser, optical and computing technologies, this novel analytic system provides information on the spatially varying compositions of all types of richly inhomogeneous solid objects - their chemical and isotopic constituents and their molecular natures automatically and swiftly, moreover with seamless 3-D microscopic resolution and precision over macroscopic scales.

Thus, it represents a fundamental advance in the human ability to better analyze, image and understand - and thus to more aptly utilize and control - the material object-oriented aspects of our physical world. This superior utility and control, expessed over a huge gamut of present-day technology-sets, inevitably will confer great benefits on all mankind, across many fields of endeavor - just as did optical microscopy and $x$-ray imaging.

Imaging for the first time the 3-D chemical-elemental and molecular structures of key biological tissues with micrometer resolution over centimeter distances may constitute the single largest impact of the present technology on either basic science or technology, but will be only one of many. 
15. To whom should reader inquiries about your product be directed?

\begin{tabular}{|c|c|}
\hline Name & Muriel Y. Ishikawa \\
\hline Position & Physicist \\
\hline Organization & Lawrence Livermore National Laboratory \\
\hline Address: & P.O. Box 808, L-278 \\
\hline Address: & 7000 East Avenue \\
\hline City: & Livermore \\
\hline State & California \\
\hline Zip & 94551 \\
\hline Country & USA \\
\hline Phone & $(925) 423-4178$ \\
\hline Fax & (925) $423-1243$ \\
\hline Email & ishikawa1@llnl.gov \\
\hline
\end{tabular}

\section{ENTRY PROCEDURE}

1. Any new technical product that was first available for purchase or licensing between Jan. 1, 2000, and Dec. 31, 2000, may be entered. Proof-of-concept models should not be entered until they reach a more advanced age. PHYSICAL EXISTENCE OF THE PRODUCT MUST BE SHOWN IN A PHOTOGRAPHS OR ACTUAL SAMPLE.

2. Answer all questions as provided in this form. Answers should be typewritten. Retyping the form to fit additional names is allowed.

3. Supporting information, such as scientific papers, patents, or articles may be added in an appendix. Highlight important information.

4. Each entry must be signed by the submitter and accompanied by a $\$ 175$ entry fee. Make checks payable to: R\&D MAGAZINE. Mail checks and EIGHT (8) COMPLETE SETS of the entry to R\&D 100 Awards, 2000 Clearwater Drive, Oak Brook, IL 60523, USA.

5. Entries will not be returned.

6. Applications due March 2, 2001. EARLY BIRD: Entries received by February 1, 2001, will be reviewed by a judging panel to see if additional information might help the judges better understand the product entry. Submitters with incomplete information will be notified by fax and allowed to submit additional information. 7. Winning products will be selected on the basis of their importance, uniqueness, and usefulness by a panel of technical experts.

8. All winners will be notified of the judges' decision by June 29,2001 . A complete report will be published in the September 2001 print and electronic issues of $R \& D$ Magazine.

9. For more information, please call 630-320-7168, fax: 630-320-7160, e-mail: tstudt@cahners.com. 


\section{Supporting Documentation}

1) List of Co-Inventors/Co-Developers

2) Letters of Support

a) Paul B. MacCready, Founder, Aeronvironment Inc.

b) Kenneth Carpenter, PaleoLab Director, Department of Earth Sciences, Denver Museum of Natural History

c) Bran Ferren, President, R\&D and Creative Technologies, Disney Imagineering R\&D (currently President, Applied Minds)

3) Commerce Business Daily, June 2000

4) Ultrashort-Pulse Laser Machining, UCRL-ID-132159, M.D. Perry, et al, September 1998

5) Marketing data sheet, 2000

6) Photos

a) Example of High-Speed 3D Object Composition Mapping (DOCMT) of a 200 grid fine copper mesh. Data from four layers, after a raster scan has removed several microns of copper during each mapping pass, are shown in descending order. Extremely fine variation and warpage of the mesh was revealed during the mapping process.

b) A DOCMT data layered cutaway of a Si Darlington bi-polar transistor before computer modeling of the object is begun. The finished 3D mapped object can be seen in the accompanying video, and is an example of this new technology.

7) News articles

a) Peeling away the Past, New Scientist, November 6, 1999

b) Lasers May Bare Bones of the Past, Tri-Valley Herald/Oakland Tribune, November 11, 1999

c) Ultrafast Laser Frees Prehistoric Fossils, Photonics Technology News, January 2000. 


\section{List of Co-Inventors/Co-Developers}

Lowell L. Wood, Jr. $\$$

Lawrence Livermore National Laboratory

7000 East Avenue, P.O. Box 808, L-278

Livermore, California 94551

Phone: (925) 422-7286 Fax: (925) 423-1243

E-mail: lowellwood@home.com

Brent C. Stuart ${ }^{\S}$

Lawrence Livermore National Laboratory

7000 East Avenue, P.O. Box 808, L-477

Livermore, California 94551

Phone: (925) 424-5782 Fax: (925) 422-5537

E-mail: stuart3@||n|.gov

J. Paul Armstrong ${ }^{\dagger}$

Lawrence Livermore National Laboratory

7000 East Avenue, P.O. Box 808, L-477

Livermore, California 94551

Phone: (925) 422-4127 Fax: (925) 422-5537

E-mail: armstrong16@linl.gov

Alexis E. Wynne ${ }^{+}$

Lawrence Livermore National Laboratory

7000 East Avenue, P.O. Box 808, L-438

Livermore, California 94551

Phone: (925) 424-2545 Fax: (925) 424-4625

E-mail: wynne2@llnl.gov

E. Michael Campbell ${ }^{\Phi}$

Michael D. Perry

\footnotetext{
${ }^{\S}$ Principal Inventor, Co-Developer

${ }^{\dagger}$ Co-Developer

${ }^{\Phi}$ Principal Inventor, no longer with LLNL.
} 
PAUL B. MACCREADY, Ph.D.

CHAIRMAN OF THE BOARD

January 28,2000

Dr. Jeffrey Wadsworth, Deputy Lab Director

University of California

Lawrence Livermore National Laboratory

P.O. Box 808-L-1

Livermore, California 94550

Dear Dr. Wadsworth:

I'm writing to convey my company's interest, as well as my own, in the "Composition Analysis by Scanned Femtosecond Laser Ultraprobing" (CASFLU) technology which is under development by your Laboratory.

Understanding in micro-scale the composition of materials and the variability thereof is of great interest in many aspects of engineering, particularly when materials will be employed in the most demanding applications, such as AeroVironment's air vehicles. Prior to the level of analytic capability represented by CASFLU, means of gaining such understanding quickly, quantitatively and over large surface areas has been limited and costly. Acquiring such composition information over substantial depth into a sample, going well into the third dimension of material analysis, has been essentially impractical. The ability represented by CASFLU to develop the empirical chemical formulae and to give major massspectrometric clues as to the molecular composition of materials, both on micro-scales and over all three spatial dimensions, seems likely to be of great practical significance.

CASFLU capabilities appeal to engineers such as myself and, I expect, to all others interested in highperformance modern materials, since it potentially provides new insights into the microscopic aspects of materials structure and composition of such materials, the key determinants of performance. We will therefore follow the development of CASFLU with keen interest. I look forward to its becoming available soon for regular commercial procurement.

I congratulate the Livermore Laboratory on this great advance in material-analytic capabilities. I believe that it may result in major advances in understanding and employing more effectively the full spectrum of modern materials.

Sincerely yours,

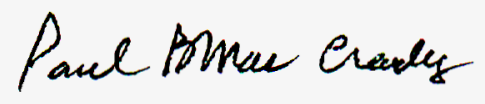

Paul B. MacCready

0100:24 
Dr. Jeffrey Wadsworth

Deputy Director for Science and Techaology

Lawrence Livermore National Laboratory

P.O. Box 808, L-1

Livermore, Califomia 94550

Dear Dr. Wadsworth:

The new Composition Analysis by Scanned Femtosecond Laser Ultraprobing (CASFI,U) technology offers intriguing possibilities for developing insight into the understanding of composition of materials, both on the microscale and in one to three spatial dimensions. CASFLU also can be used, because of its microscalc analytic abilities, in the retrieval and microdissection of valuable, sometimes irreplaceable fossils and artifacts embedded in various matrix material.

I encourage your Laboratory to invest in making the CASFLU technology readily available to the public and private sectors. This type of new technology offers museums and scientists in the paleontological and related disciplines new options in materials processing applications, and may rcsult in significant time and resource savings in the conduct of ground-breaking research.

Sincerely,




February 15,2000

Dr. Jeffrey Wadsworth, Deputy Lab Director

University of California Lawrence Livermore National Laboratory

P.O. Box $808-L-1$

Livermore CA 54550

Dear Dr. Wadsiworth:

I'm writing to express the interest of my organization in the "Composition Analysis by Scanned Femtosecond Laser Ultraprobing" (CASFLU) technology which your Laboratory has recently developed.

As you appreciate, understanding in micro-scale the (variable) composition of materlals is of the broadest possible interest in materials engineering, particularly when materials will be employed in the mosi demanding applications, as my organization often does. Before the advent of CASFLL, means of garning such understanding - particularly in quantitative terms and over large sample areas - has been remarkably tedious and expensive. Also gaining such information over substantial depth - going into the thiro dimension of samples to any significant extent - nas been essentially impractical. GASFLU's ability to simulaneously present both chemical-elemental and molecular composition information is effectively unique - and is of enormous practical significance.

At our enterprise I can see a variety of applications in failure analysis, environmental sciences, and as a tool to and our research staff. At present we employ a variety of separate techniques that are often tedious and error prone, especially when there is a requirement for merging dissimilar data collections (with marginally compatible, manufacturer proprletary database formats) for large specimens.

CASFLU capabilities thus offer us - and all other interested in high-performance modem materials - entirely new visias on the micro-scale aspects of materials structure and composition, and thus the performance of such materials. We will therefore follow the development of CASFLU with great interest, and will look forward to its being available in the near-term for procurement from full-suppor commercial sources.

I congratulate your Laboratory on this qualitative advance in analytic capabilities, which I expect will confer major benefits on everyone seeking to better understand and more effectively employ modern materials.

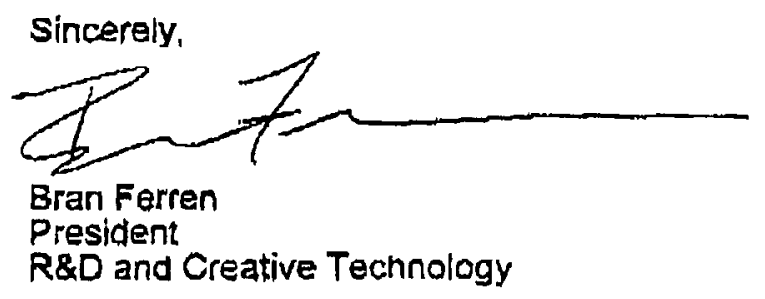

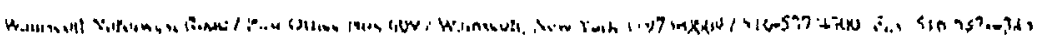

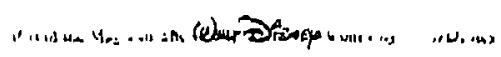




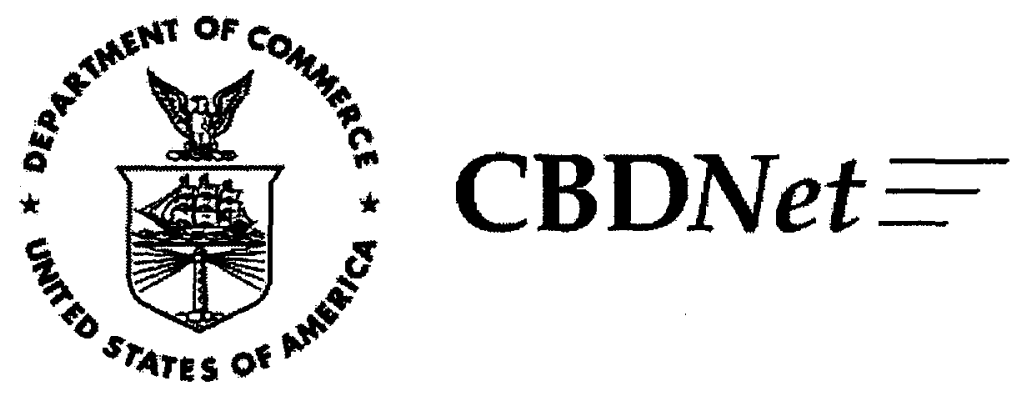

\section{Notice Accepted}

Submission No. 464676

June 14, 2000 -- 13:21

[Commerce Business Daily: Posted in CBDNet on June 14, 2000]

From the Commerce Business Daily Online via GPO Access

[cbdnet.access.gpo.gov]

PART: U.S. GOVERNMENT PROCUREMENTS

SUBPART: SERVICES

CLASSCOD: A--Research and Development
OFFADD: Lawrence Livermore National Laboratory, 7000 East Avenue,

Livermore, CA 94550

- SUBJECT: A--LAWRENCE LIVERMORE NATIONAL LABORATORY SEEKS INDUSTRIAL PARTNERS TO COMMERCIALIZE A NEW LASER TECHNOLOGY.

SOL $00-019$

DUE 081400

POC Industrial Partnership and Commercialization (925) 423-3139

- DESC: The Lawrence Livermore National Laboratory (LLNL), operated

by the University of California under contract with the U.S.

Department of Energy is seeking industrial partners to commercialize

and license Composition Analysis by Scanning Femtosecond Laser

Ultraprobing (CASFLU), a new laser technology. CASFLU exploits

a new phenomenon, only discovered in the past half-decade,

that enables computer-automated, high-speed, ultra-high spatial-resolution

analysis of the molecular, chemical-elemental and isotopic

compositions of complex three-dimensional (3-D) objects of

all types, shapes and compositions. Many of t CASFLU capabilities

are novel, and may offer advances in analytic capability comparable

to those first presented by invention of the microscope. CASFLU

is expected to provide: (1) 3-D Ablative Micro-Dissection of

Objects, (2) Composition Analysis (3) Precise 3-D Object Dissection

(4) Extracting objects Embedded Within Solids. "CASFLU is

based upon the use of exceedingly intense [ $>10 * * 13 \mathrm{Watts} / \mathrm{cm} * \star 2]$

laser pulses of extremely brief duration $\left[<10^{\star \star}(-12)\right.$ seconds

each] to heat the uppermost layer [thicknesses < 1 micrometer,

or $10^{* *}(-4) \mathrm{cm}$ ] of any type of material to temperatures far

above the vaporization point [temperatures typically $-10,000$

$\mathrm{K}$ ) ; roughly 1 Joule/ $\mathrm{cm} \star \star 2$ of pulsed laser fluence is involved

in each event. When material is so abruptly heated over this

temperature range, the heated material evaporates so swiftly

that it doesn't have time to "leak" its thermal energy into

surrounding material, which is thus left essentially unchanged

by the ablative removal of the vaporized material -- and therefore

available for subsequent processing in quite pristine condition.

The vaporized material originates only from the spot which

- has been laser beam-heated, and the composition of this super-heated

vapor thus reflects that of the heated spot. Analysis of this

composition by optical- or mass-spectrometric means thus permits

the composition of exceedingly tiny mass-parcels $[-10 * \star(-12)$

$\mathrm{cm}^{* * 3]}$ to be determined, as the focal spot-diameter may be

made as small as the wavelength of the light employed [typically

< 1 micrometer]. Since the repetition-rate of the laser pulses

may be made very high $[<10 * * 8 /$ second], time-average mass-remova]

rates may be quite high, without sacrifice of micron-scale

spatial resolution. Scanning of the focused laser beam -- or

of the object being analyzed under a fixed beam -- may be used

to successively generate one-, two- and three-dimensional

composition maps of the object being analyzed." It may be

possible to apply CASFLU to analytical science and engineering.

Its primary application is expected to be in the analyses of

the position-dependent molecular, chemical-elemental and isotopic

compositions of 2- and 3-dimensional objects of all types.

CASFLU offers potential to companies working with the U.S.

stockpile Stewardship program, Magnetic Fusion Energy Program,

and 3-D, composition-analyses of biological tissues on microscopic

scales in Energy Research projects. Companies working with

the FBI and associated state and local law-enforcement agencies

may find CASFLU a useful tool for unique object micro-analysis

capabilities. Companies interested in working with LLNL to

statement of interest that includes a description of corporate

capability relevant to commercialization of the technology

and basic corporate information. Respondents are encouraged 
to provide ancillary documentation such as annual reports,

corporate resumes, and technical publications. THIS IS NOT

A PROCUREMENT. All Letters of Interest must be received within

60 days of this announcement. Please send Letters of Interest

to Joseph Milner, Business Development Specialist, Lawrence

Livermore National Laboratory, 7000 East Avenue, Mail stop

L795, Livermore CA 94550-9234, Attention: CBD-00-019.

CITE: (W-166 SN464676)

CBDNet is provided through an alliance of the United States Department of Commerce and the United States Government Printing Office.

Questions or comments regarding this service? Contact the GPO Access User Support Team by Internet e-mail at cbd-support@gpo.gov or toll-free at 1-888-293-6498.

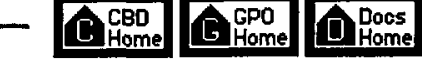

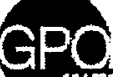

URL: http://cbdnet.gpo.gov/ACCEPT.template

- LAST MODIFIED: February 18, 1997 by JER 


\section{Ultrashort-Pulse Laser Machining}

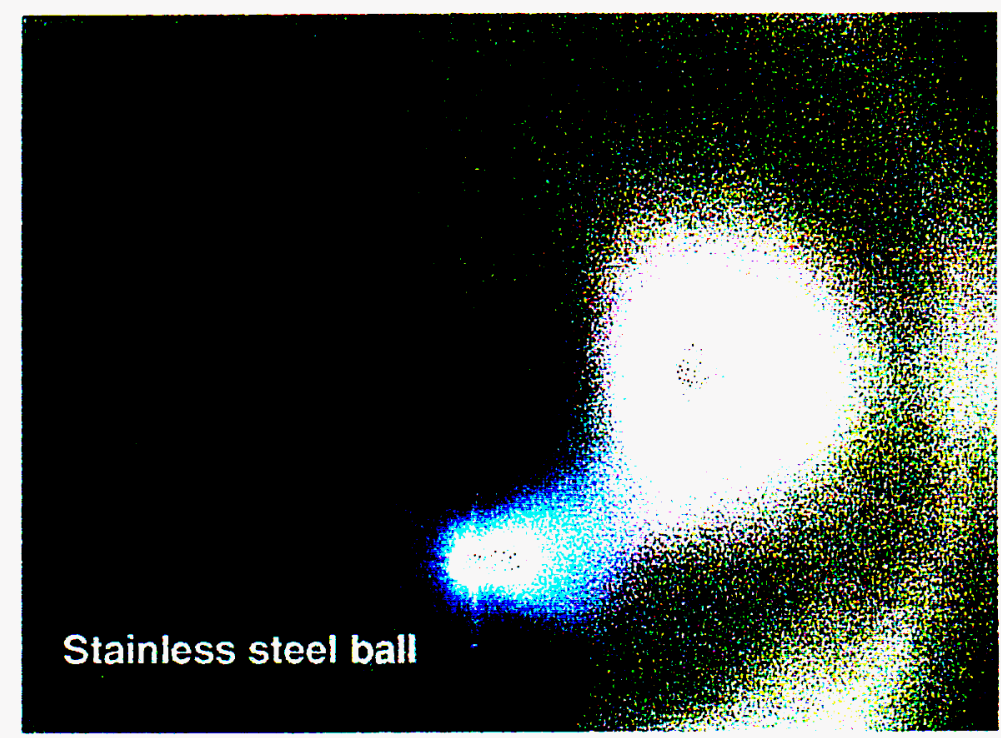

September 1998 


\section{DISCLAIMER}

This document was prepared as an account of work sponsored by an agency of the United States Goveroment. Neither the United States Goverument nor the University of California nor any of their employees, makes any warranty, express or implied, or assumes any legal liability or responsibility for the accuracy, completeness, or usefulness of any information, apparatus, product, or process disclosed, or represents that its use would not infringe privately owned rights. Reference herein to any specific commercial product, process, or service by trade name, trademark, manufacturer, or otherwise, does not necessarily constitute or imply its endorsement, recommendation, or favoring by the United States Government or the University of California. The views and opinions of authors expressed herein do not necessarily state or reflect those of the United States Government or the University of California, and shall not be used for advertising or product endorsement purposes.

This report has been reproduced directly from the best available copy.

Available to DOE and DOE contractors from the Office of Scientific and Technical Information

P.O. Box 62, Oak Ridge, TN 37831

Prices available from (615) 576-8401, FTS 626-8401

Available to the public from the

National Technical Information Service

U.S. Department of Commerce

5285 Port Royal Rd.

Springfield, VA 22161

Work performed under the auspices of the U.S. Department of Energy by Lawrence Livermore National Laboratory under Contract W-7405-ENG-48. 


\title{
Ultrashort-Pulse Laser Machining
}

\author{
M.D. Perry, B.C. Stuart, P.S. Banks, H.T. Nguyen, \\ M.D. Feit, A.M. Rubenchik, and J.A. Sefcik
}

September 1998

Cover photo: Femtosecond laser system machining stainless steel. Femtosecond lasers cut without melting or collateral damage. 


\section{Contents}

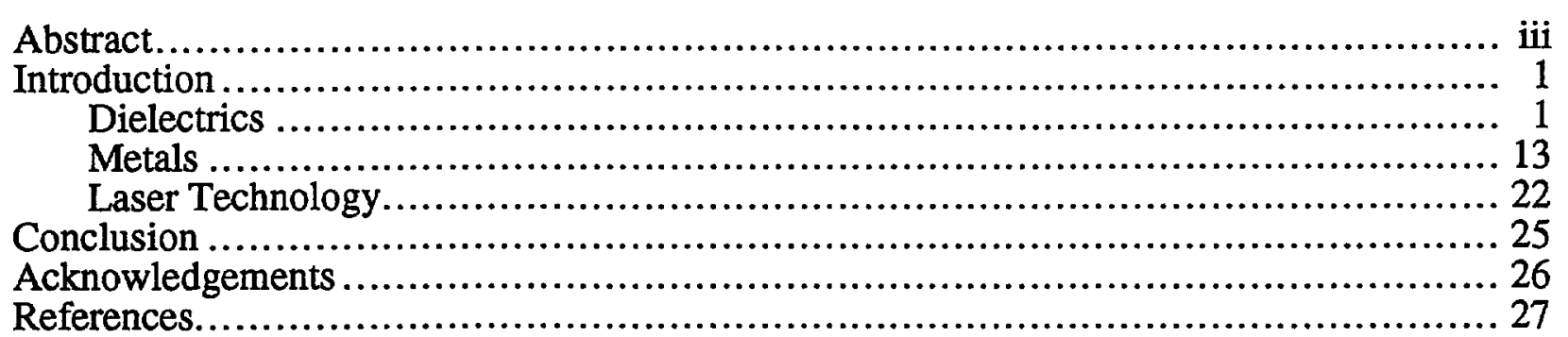




\section{List of Figures}

Figure 1. (a) Drilling of enamel (tooth) with conventional $1053 \mathrm{~nm}$, nanosecond pulses (ablation threshold $=30 \mathrm{~J} / \mathrm{cm}^{2}$ for $\mathrm{p}=2 \mathrm{nsec}$ ) .............................. 3

Figure 2. Observed values of damage threshold at $1053 \mathrm{~nm}$ for fused silica $(\bullet)$ and $\mathrm{CaF} 2(\diamond)$

Figure 3. Schematic of collisional ionization with the approximation that the kinetic energy in the final state is shared equally by the electrons

Figure 4. Calculated evolution of free electron density for a 100-fs, 1053-nm pulse (dashed curve) of peak irradiance $=10 \mathrm{TW} / \mathrm{cm}^{2}$ in fused silica

Figure 5. Reflectivity of fused silica surface as a function of laser irradiance for $\lambda=1053 \mathrm{~nm}$ and $\tau_{\mathrm{p}}=350 \mathrm{fs}$

Figure 6. Measured and calculated damage thresholds of fused silica in the infrared and visible (526 $\mathrm{nm}$ )

Figure 7. Temperature increase of bulk tooth due to drilling with 1.4-nanosecond (circles) and 350-femtosecond (squares) laser pulses

Figure 8. Cuts in explosive pellet (PETN) by a Ti:sapphire laser operating at $120 \mathrm{fs}$ (a) and $0.6 \mathrm{~ns}$ (b) .

Figure 9. Cuts in stainless steel performed with $1054 \mathrm{~nm}$ laser pulses with a duration of (a) $1.4 \mathrm{~ns}$ at a fluence of $52 \mathrm{~J} / \mathrm{cm}^{2}$ and (b) $350 \mathrm{fs}$ and $14 \mathrm{~J} / \mathrm{cm}^{2}$ 14

Figure 10. Calculated temperature profiles in gold irradiated at $1054 \mathrm{~nm}$ and a fluence of $0.5 \mathrm{~J} / \mathrm{cm}^{2}$ for 1,10 , and 100 ps pulses

Figure 11. Damage threshold of gold at $1054 \mathrm{~nm}$ as a function of pulse duration [from ref. 29]

Figure 12. Calculated temperature (a) and pressure (b) of aluminum irradiated by $1053-\mathrm{nm}, 350-\mathrm{fs}$ laser pulses at a fluence of $5 \mathrm{~J} / \mathrm{cm}^{2}$

Figure 13. Calculated temperature (a) and pressure (b) of aluminum following irradiation by $1053-\mathrm{nm}, 350$-fs laser pulses at a fluence of $5 \mathrm{~J} / \mathrm{cm}^{2}$

Figure 14. Calculated temperature (a) and pressure (b) of aluminum following irradiation by a $1053-\mathrm{nm}, 1-\mathrm{ns}$ laser pulse at a fluence of $20 \mathrm{~J} / \mathrm{cm}^{2}$ (same depth of material removed as in Figure 13)

Figure 15. Depth of material removed per laser pulse for stainless steel and $\lambda=825 \mathrm{~nm}$

Figure 16. Holes drilled through $1 \mathrm{~mm}$ stainless steel with 120 -fs laser pulses at $1 \mathrm{kHz}$ at $45^{\circ}$

Figure 17. Holes drilled through $1 \mathrm{~mm}$ stainless steel for fuel injector nozzles 24

Figure 18. Photograph of a 15-W average power femtosecond laser machining system developed for industrial operation 


\begin{abstract}
A new type of material processing is enabled with ultrashort $(t<10 \mathrm{ps})$ laser pulses. Cutting, drilling, sculpting of all materials (biologic materials, ceramics, sapphire, silicon carbide, diamond, metals) occurs by new mechanisms that eliminate thermal shock or collateral damage. High-precision machining to submicron tolerances is enabled resulting in high surface quality and negligible heat affected zone.
\end{abstract}




\section{Introduction}

Conventional mechanical lathes and machine tools are effective for machining simplified shapes (cutting, drilling) in metals down to approximately $200-\mu \mathrm{m}$ (8 mil) kerf width at depths of approximately $1 \mathrm{~mm}$ (aspect ratio <5:1). For finer features or irregular shapes, electron beam, electron discharge (EDM) or conventional laser tools are typically used. Conventional laser tools such as those based on $\mathrm{CO}_{2}, \mathrm{Nd}: \mathrm{YAG}$, or copper vapor lasers machine materials by localized heating. Both EDM and existing industrial laser technology heat the material to the melting or boiling point resulting in thermal stress to the remaining material and often a heat affected zone. Higher precision or higher aspect ratio (e.g., $100-\mu \mathrm{m}$ holes thru $1 \mathrm{~mm}$ steel) is difficult to achieve with these techniques. Furthermore, non-metals (e.g., ceramics, SiC, diamond, sapphire, bone, etc) are very difficult to machine using EDM or conventional laser processing. Laser processing by molecular dissociation in organic (and some inorganic) materials can be achieved with ultraviolet lasers (e.g., excimer lasers- $\mathrm{KrF}, \mathrm{XeCl}$ ) but this photodissociation mechanism is not applicable to metals.

By using ultrashort ( $\tau<10 \mathrm{ps)} \mathrm{laser} \mathrm{pulses} \mathrm{any} \mathrm{material} \mathrm{can} \mathrm{be} \mathrm{machined} \mathrm{to} \mathrm{very} \mathrm{high}$ precision. The ability to machine any material-including high bandgap dielectrics such as $\mathrm{SiC}$, diamond, etc.-is a result of the fact that these ultrashort pulses interact by a mechanism that is very different from that of conventional longer pulse lasers. This interaction is independent of the usual linear absorption properties of the material and is applicable to materials which would otherwise be transparent to the laser wavelength. Machining to micron-scale $(<0.1 \mathrm{mil})$ precision with no collateral damage to the remaining material is achieved by removing material faster than heat can be conducted to the bulk.

In an effort to introduce the concepts and challenges associated with ultrashort-laser machining, we have divided this article is into three basic sections: machining of dielectrics; machining of metals; and laser technology.

\section{Dielectrics}

By dielectrics, we generally are referring to materials with no free electrons and low thermal/electrical conductivity. Common materials such as fused silica, sapphire, $\mathrm{SiC}$, diamond, $\mathrm{SiN}$, AlTiC, $\mathrm{ZrO}_{2}$, glass, plastic, bone, cornea, heart tissue, etc. would fall under this category. Semiconductors such as silicon and gallium arsenide would generally not be considered dielectrics by this definition. However, these materials behave similar to dielectrics when machining with ultrashort laser pulses.

Attempts to machine dielectrics with lasers followed shortly after laser induced damage was observed in transparent solids. ${ }^{1-5}$ For pulses longer than a few tens of picoseconds, the generally accepted picture of damage to dielectrics involves the heating of seed electrons by the incident radiation and transfer of this energy to the lattice. Damage occurs via conventional heat deposition resulting in melting and boiling of the dielectric material. Because the controlling rate is that of thermal conduction through the lattice, this model predicts a $\tau^{1 / 2}$ dependence of the 
threshold fluence (energy/area) upon pulse duration $\tau,{ }^{6}$ in reasonably good agreement with numerous experiments which have observed a $\tau^{\alpha}$ scaling with $0.4<\alpha<0.5$ in a variety of dielectric materials from 100 ps to microseconds. ${ }^{7}$ With these conventional lasers, material is removed by thermal ablation wherein the material is locally heated to near the boiling point. Since the boiling point of these materials is very high (typically $>1000^{\circ} \mathrm{C}$ ), this ablation mechanism is accompanied by a strong thermal shock to the remaining bulk material. This thermal shock often results in cracking of the remaining material and uncontrolled material removal. These effects can be observed in Figure 1 where the initial stages of hole drilling in a tooth using a conventional Nd:YAG laser are shown. In Figure 1a, linear absorption due to defects produces inhomogeneous energy absorption across the laser beam. Thermal stresses increase to the point where ablation begins first from the point with the least material strength.

It had been postulated that the $\tau^{1 / 2}$ dependence of the laser damage threshold for dielectrics would break down for pulse durations less than a few picoseconds as the probability of multiphoton ionization of the individual atoms within the dielectric became significant. ${ }^{8}$ In order to quantify the transition from a thermal mechanism of damage to one associated with direct ionization, we began a systematic study of the damage threshold in a variety of dielectric materials in 1993. In all dielectrics which we examined, a strong deviation from the $\tau^{1 / 2}$ dependence of the damage threshold was observed. This deviation occurred in a range from 10 ps $\left(\mathrm{SiO}_{2}\right)$ to $\approx 20 \mathrm{ps}\left(\mathrm{CaF}_{2}\right)$ as shown in Figure $2.9^{9}$

In all cases, the deviation was accompanied by a dramatic change in morphology of the damaged surface (Figure 1b). With femtosecond pulses, all regions throughout the laser beam profile with sufficient intensity for multiphoton ionization will be removed resulting in extremely fine control of the position of material removal. In addition, the morphology of the surface drilled with femtosecond pulses is characteristic of the internal enamel and dentin. There is no evidence of heat transfer into the surrounding material and no thermal shock cracking in any of the surrounding material (Figure 1c).

Both the change in surface morphology and the deviation from the $\tau^{1 / 2}$ dependence of the damage threshold on pulse duration are predicted by a rapid ionization mechanism. ${ }^{9}$ We will consider fused silica in greater detail in order to describe the model with a specific material. Damage occurs at a threshold of $\approx 2 \mathrm{~J} / \mathrm{cm}^{2}$ for a 1-ps pulse (Figure 2). With an irradiance of $2 \times 10^{12} \mathrm{~W} / \mathrm{cm}^{2}$, there is no need to invoke some arbitrary number of initial "seed" electrons. ${ }^{1-5,10,11}$ Field-induced multiphoton ionization produces free electrons which are then rapidly accelerated by the laser pulse. For these very short, intense pulses, energy is gained by the newly free electrons from the laser field much faster than it is transferred from the electrons to the lattice. These electrons gain energy from the laser field until they have sufficient energy to 

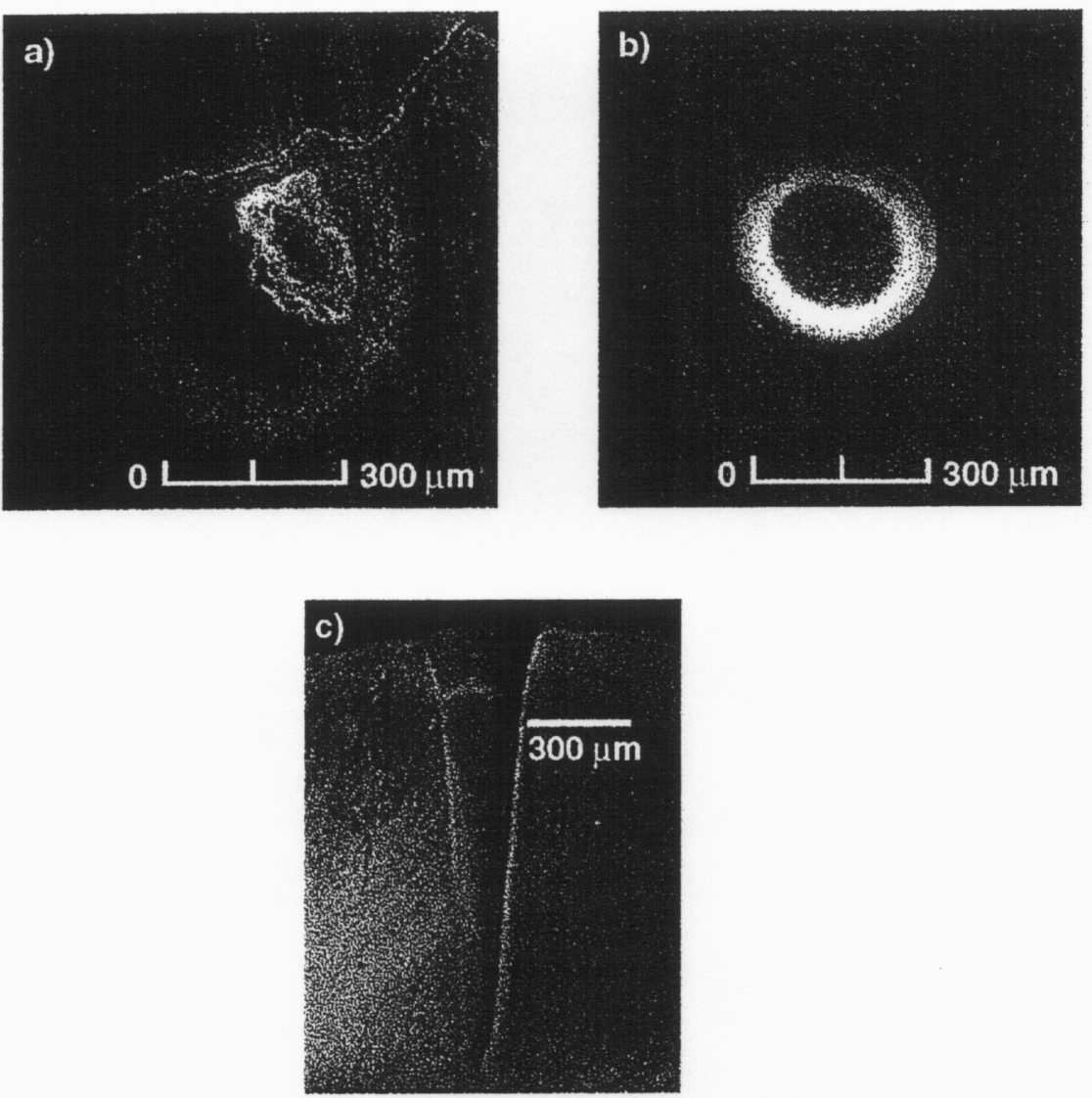

Figure 1. (a) Drilling of enamel (tooth) with conventional $1053 \mathrm{~nm}$, nanosecond pulses (ablation threshold $=30 \mathrm{~J} / \mathrm{cm}^{2}$ for $\mathrm{p}=\mathbf{2} \mathrm{nsec}$ ). (b) Same as in (a) but with the pulse duration reduced to the ultrashort regime (ablation threshold $=3 \mathrm{~J} / \mathrm{cm}^{2}$ or $\mathrm{p}=0.35 \mathrm{ps}$ ). In both cases, the laser spot size was $300 \mathrm{~m}$. (c) cross section of hole made with $350 \mathrm{fs}$ pulses.

collisionally ionize neighboring atoms thereby producing more free electrons. This process continues until a critical density plasma is reached wherein no further energy deposition from the laser occurs. The actual damage occurs after the pulse has passed, when the dense plasma expands away from the surface.

Plasma formation is quantitatively described by the time dependence of the electron energy distribution function. Since the impact ionization rate is energy dependent, the absorption rate of laser energy requires integrating over the electron energy distribution. When the electrons are strongly driven by intense laser pulses, the energy distribution can differ substantially from a Maxwellian. For material having a bandgap energy that is much larger than the single photon 


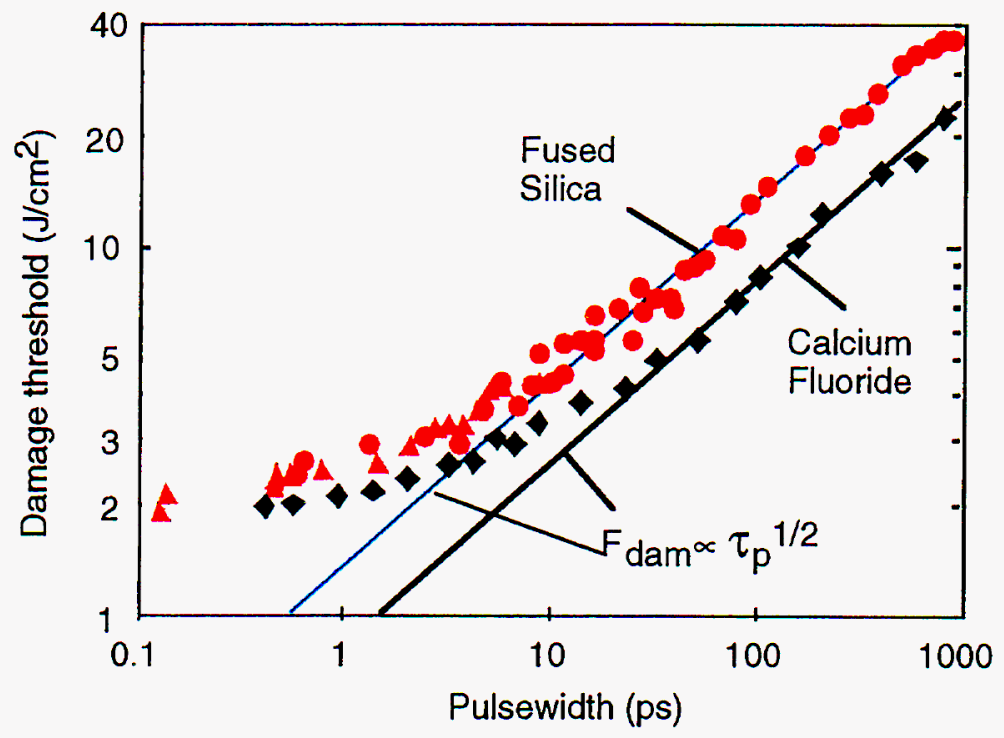

Figure 2. Observed values of damage threshold at $1053 \mathrm{~nm}$ for fused silica (๑) and CaF2 $(\diamond)$. Solid lines are 1/2 fits to long pulse results, dashed line is fluence required to cause damage in $\mathrm{SiO} 2$ by photoionization alone. Estimated absolute error in data is $\pm \mathbf{1 5 \%}$.

energy, $U_{I} \gg \hbar \omega$, heating and collisional ionization of conduction electrons can be described by a Fokker-Planck equation ${ }^{5,12}$ for the electron distribution function $\mathrm{N}(\varepsilon, t)$,

$$
\frac{\partial N(\varepsilon, t)}{\partial t}+\frac{\partial}{\partial \varepsilon}\left[R_{J}(\varepsilon, t) N(\varepsilon, t)-\gamma(\varepsilon) E_{P} N(\varepsilon, t)-D(\varepsilon, t) \frac{\partial N(\varepsilon, t)}{\partial \varepsilon}\right]=S(\varepsilon, t)
$$

where $\varepsilon$ is the electron kinetic energy. The number of electrons with a kinetic energy in the range, $\varepsilon$ to $\varepsilon+d \varepsilon$ at the time, $t$, is given by $\mathrm{N}(\varepsilon, \mathrm{t}) \mathrm{d} \varepsilon$. The square bracket in Eq. 1 represents the change in the electron distribution due to Joule heating, inelastic scattering of phonons, and electron energy diffusion. The Joule heating rate of the electrons is given by,

$$
\mathrm{R}_{\mathrm{J}}(\varepsilon, \mathrm{t})=\frac{\sigma(\varepsilon)}{3} \mathrm{E}_{\mathrm{rms}}(\mathrm{t})^{2}
$$

where $E_{\mathrm{rms}}(\mathrm{t})$ is the electric field of the laser and $\sigma(\varepsilon)=\mathrm{e}^{2} \tau_{\mathrm{m}}(\varepsilon) / \mathrm{m}^{*}\left[1+\omega^{2} \tau_{\mathrm{m}}(\varepsilon)^{2}\right]$ is the ac conductivity of a conduction-band electron of effective mass $m^{*}$. Here, $v_{m}(\varepsilon)=1 / \tau_{m}(\varepsilon)$ is the energy-dependent, electron-phonon transport (momentum) scattering rate. It is instructive to rewrite this expression as

$$
\mathrm{R}_{\mathrm{J}}(\varepsilon, \mathrm{t})=v_{\mathrm{coll}}(\varepsilon) \frac{\mathrm{e}^{2} \mathrm{E}(\mathrm{t})^{2}}{4 \mathrm{~m} \omega^{2}}=v_{\mathrm{coll}}(\varepsilon) \mathrm{U}_{\mathrm{p}}
$$


where $U_{p}=e^{2} E(t)^{2} / 4 \mathrm{~m} \omega^{2}=9.33 \times 10^{-14} \mathrm{I}\left(\mathrm{W} / \mathrm{cm}^{2}\right) \lambda^{2}(\mu \mathrm{m})$, is the free electron quiver energy expressed in $\mathrm{eV}$ and $v_{\text {coll }}(\varepsilon)=v_{\mathrm{m}}(\varepsilon)^{*}\left\{\omega^{2} \tau_{\mathrm{m}}(\varepsilon)^{2} /\left[1+\omega^{2} \tau_{\mathrm{m}}(\varepsilon)^{2}\right\} \approx v_{\mathrm{m}}(\varepsilon)\right.$ is the effective electron collision frequency with the lattice. For $\mathrm{SiO}_{2}$, the momentum scattering rate, $\mathrm{Ym}(\varepsilon)$, varies between $2 \mathrm{fs}^{-1}$ and $10 \mathrm{fs}^{-1}$ from 1 to $10 \mathrm{eV} \cdot{ }^{13}$ Hence, for a laser wavelength of $1064 \mathrm{~nm}$ and an intensity of $10^{13} \mathrm{~W} / \mathrm{cm}^{2}$, the single electron heating rate is on the order of a few eV/fs.

The rate of energy transfer from the electrons to the lattice is given by the second term within the brackets, $\gamma(\varepsilon) E_{\mathrm{p}} N(\varepsilon, \mathrm{t})$, where $E_{\mathrm{p}}$ is the energy of a typical phonon and $\gamma(\varepsilon)$ is the rate of electron-phonon energy transfer to the lattice. Note that for pulses on the order of $1 \mathrm{TW} / \mathrm{cm}^{2}$, the electron heating rate, $\mathrm{R}_{\mathrm{J}}(\varepsilon, t)$ is much greater than the rate of energy transfer to the lattice, $\gamma(\varepsilon) E_{\mathrm{p}}$ The term $D(\varepsilon, t) \partial N / \partial \varepsilon$ represents electron energy diffusion with a diffusion coefficient given by $\mathrm{D}(\varepsilon, \mathrm{t})=2 \varepsilon \mathrm{R}_{\mathrm{J}}(\varepsilon, \mathrm{t})$.

The final term represents sources and sinks of electrons. Specifically, the total number of electrons created with kinetic energy in the range, $\varepsilon$ to $\varepsilon+d \varepsilon$ at the time, $t$, is given by $S(\varepsilon, t) d \varepsilon$. Free electrons can be created by both multiphoton ionization and collisional (impact) ionization. Electrons that have been accelerated to energies above the ionization potential, $\mathrm{U}_{\mathrm{IP}}$, can collisionally ionize a neighboring atom. An incident electron of kinetic energy, $\varepsilon_{0}=2 \varepsilon+\mathrm{U}_{\mathrm{IP}}$, produces two free electrons of energy, $\varepsilon$, and an ion (hole) of potential energy, $U_{\text {IP }}$ in the final state (Figure 3). Impact ionization occurs at a rate described by the Keldysh impact formula ${ }^{14}$, $v_{\mathrm{I}}\left(\varepsilon_{0}\right)=\chi\left(\varepsilon_{0} / \mathrm{U}_{\mathrm{IP}}-1\right)^{2}$. For fused silica, the proportionality constant, $\chi=1.5 \times 10^{15} \mathrm{sec}^{-1}$ for incident electrons of energy $<100 \mathrm{eV} .13$

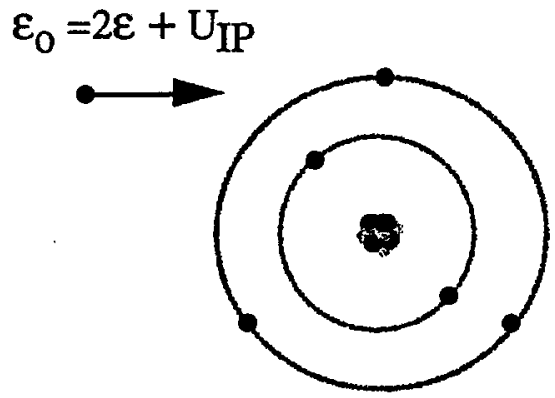

Initial

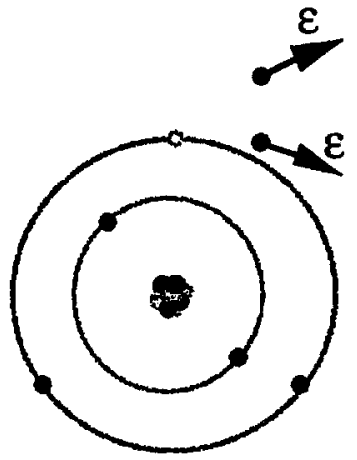

Final

Figure 3. Schematic of collisional ionization with the approximation that the kinetic energy in the final state is shared equally by the electrons. 
The source term for impact ionization can be written as, ${ }^{12}$

$$
\begin{aligned}
\mathrm{S}(\varepsilon, \mathrm{t})_{\text {impact }} \mathrm{d} \varepsilon & =2 \mathrm{~N}\left(\varepsilon_{\mathrm{o}}, \mathrm{t}\right) \mathrm{V}_{\mathrm{I}}\left(\varepsilon_{\mathrm{o}}\right) \mathrm{d} \varepsilon_{\mathrm{o}}-\mathrm{N}(\varepsilon, \mathrm{t}) \mathrm{V}_{\mathrm{I}}(\varepsilon) \mathrm{d} \varepsilon \\
& =\left[4 \mathrm{~N}\left(2 \varepsilon+\mathrm{U}_{\mathrm{IP}}, \mathrm{t}\right) \mathrm{V}_{\mathrm{I}}\left(2 \varepsilon+\mathrm{U}_{\mathrm{IP}}\right)-\mathrm{N}(\varepsilon, \mathrm{t}) \mathrm{V}_{\mathrm{I}}(\varepsilon)\right] \mathrm{d} \varepsilon
\end{aligned}
$$

The term, $4 N\left(2 \varepsilon+U_{I P}, t\right) v_{I}\left(2 \varepsilon+U_{I P}\right)$ represents those electrons born into $\varepsilon$ to $\varepsilon+d \varepsilon$ by impact ionization, while the term, $N(\varepsilon, t) \vee_{\mathfrak{I}}(\varepsilon)$ represents those that are lost from this energy bin. The factor of four in the source term can be understood simply from the fact that the two electrons born into $\varepsilon$ to $\varepsilon+\mathrm{d} \varepsilon$ from the initial energy, $\varepsilon_{0}=2 \varepsilon+\mathrm{U}_{\mathrm{IP}}$ are born into an energy bin, $\mathrm{d} \varepsilon$ which is only half as large as the original (e.g., $\mathrm{d} \varepsilon_{0}=2 \mathrm{~d} \varepsilon$ ).

The total source term is given by,

$$
\begin{aligned}
S(\varepsilon, t) d \varepsilon & =\left[S(\varepsilon, t)_{\mathrm{PI}}+S(\varepsilon, t)_{\text {impact }}\right] \mathrm{d} \varepsilon \\
& =\left[S(\varepsilon, t)_{\mathrm{PI}}+4 N\left(2 \varepsilon+\mathrm{U}_{\mathrm{IP}}, \mathrm{t}\right) \mathrm{V}_{\mathrm{I}}\left(2 \varepsilon+\mathrm{U}_{\mathrm{IP}}\right)-\mathrm{N}(\varepsilon, \mathrm{t}) \mathrm{V}_{\mathrm{I}}(\varepsilon)\right] \mathrm{d} \varepsilon
\end{aligned}
$$

The photoionization source term, $S(\varepsilon, t)_{\mathrm{PI}}$ d $\varepsilon$ has been studied extensively in the case of isolated atoms. In the limit that the bandgap of the material is not too much greater than the photon energy, $\mathrm{UIP}_{\mathrm{IP}} / \mathrm{h} v<4$, and there are no intermediate resonances, simple perturbation theory can be used: $S(\varepsilon, t)_{\mathrm{PI}} \mathrm{d} \varepsilon=\sigma^{(\mathrm{K}))^{\mathrm{K}}}$ where $\mathrm{K}$ is the number of photons required to ionize the atom, $\sigma^{(\mathrm{K})}$ is the multiphoton ionization cross section, and I is the photon flux (photons $/ \mathrm{cm}^{2} \mathrm{sec}$ ). The energy of the resulting electron is $\varepsilon=\mathrm{Kh} v-\mathrm{U}_{\mathrm{IP}}$. An example of this case would be fused silica irradiated by $532 \mathrm{~nm}$ light. Four $2.33 \mathrm{eV}$ photons are required to ionize an $\mathrm{SiO}_{2}$ molecule $\left(\mathrm{E}_{\mathrm{b}}=9\right.$ $\mathrm{eV}$ ) with a cross section similar to that measured for $\mathrm{NaCl}, \sigma^{(4)}=2 \times 10^{-114} \mathrm{~cm}^{8} / \mathrm{sec}^{3}$. [Ref. I] If there are intermediate multiphoton resonances involved, more sophisticated expressions for the ionization rate are required. ${ }^{15}$ In the limit that the ionization potential is less than approximately twice the free electron quiver energy, $\mathrm{U}_{\mathrm{IP}}<2 \mathrm{U}_{\mathrm{P}}$, perturbation theory breaks down. Photoionization is then described by the tunneling theory of Keldysh ${ }^{16}$ or derivatives thereof. ${ }^{17,18}$

Direct numerical solution of eq. 1 can be found in ref. 19. However, a very useful approximate solution can be obtained for the total electron density, $N(t)$, in the limit that the electron heating rate is much greater than the rate of energy transfer to the lattice. Note that,

$$
\frac{\mathrm{dN}(\mathrm{t})}{\mathrm{dt}}=\frac{\partial}{\partial \mathrm{t}} \int_{0}^{\infty} \mathrm{N}(\varepsilon, \mathrm{t}) \mathrm{d} \varepsilon
$$


Inserting equations 2-5 into eq. 1 and integrating over energy, we can write the time dependence of the electron density as,

$$
\frac{d N(t)}{d t}=\beta(I) N(t)+P(I)
$$

where $\beta=\alpha I(t)$ contains all the terms associated with electron heating and impact ionization and $\mathrm{P}(\mathrm{I})$ is the photoionization term,

$$
P(I)=\int_{0}^{\infty} S(\varepsilon, t)_{P I} d \varepsilon=N_{0} W(t)
$$

where the term $N_{0}$ is the initial atom density and $W(t)$ is the single atom photoionization rate. Equation 7 is readily solved to yield,

$$
N(t)=N_{0} \operatorname{Exp}\left[\alpha \int^{t} I\left(t^{\prime}\right) d^{\prime}\right] * \int_{-\infty}^{-t} W\left(t^{\prime}\right) \operatorname{Exp}\left[-\alpha \int^{t^{\prime}} I\left(t^{\prime \prime}\right) d t^{\prime \prime}\right] d t^{\prime}
$$

The avalanche coefficient, $\alpha \approx 0.011 \mathrm{~cm}^{2} \mathrm{ps}^{-1} / \mathrm{GW}$ for fused silica, is found by numerically solving Eq. $1^{9,19}$ or by fitting the experimental data. Note that $1 / \alpha=0.1 \mathrm{~J} / \mathrm{cm}^{2}$ has the units of fluence. Many mode-locked short-pulse lasers exhibit a temporal distribution given by,

$$
I(t)=I_{o} \operatorname{sech}^{2}\left(2 t / \tau_{p}\right)
$$

Inserting this expression into eq. 9 yields,

$N(t)=N_{0} \operatorname{Exp}\left[\left(\frac{\alpha I_{o} \tau_{p}}{2}\right) \tanh \left(2 t / \tau_{p}\right)\right] * \int_{-\infty}^{-t} W\left(t^{\prime}\right) \operatorname{Exp}\left[-\left(\frac{\alpha I_{o} \tau_{p}}{2}\right) \tanh \left(2 t^{\prime} / \tau_{p}\right)\right] d t^{\prime}$

This is a very useful analytic expression that predicts the time-dependent electron density from both multiphoton and collisional ionization given an expression for the single-atom multiphoton ionization rate, $W(t)$.

Figure 4 shows the evolution of electron density for a $10 \mathrm{TW} / \mathrm{cm}^{2}, 100$-fs pulse incident on fused silica. The temporal profile of the laser pulse and the electron density produced by multiphoton ionization alone are included for reference. Because multiphoton ionization is strongly intensity dependent, the electron production takes place principally at the peak of the pulse. For this 100-fs duration, multiphoton ionization produces a substantial amount of free electrons. When the electron density produced by multiphoton ionization approaches $\approx 10^{17} \mathrm{~cm}^{-3}$, the collisional ionization rate begins to exceed the multiphoton ionization rate. Once a high free electron density is produced by multiphoton ionization the material no longer has the properties 


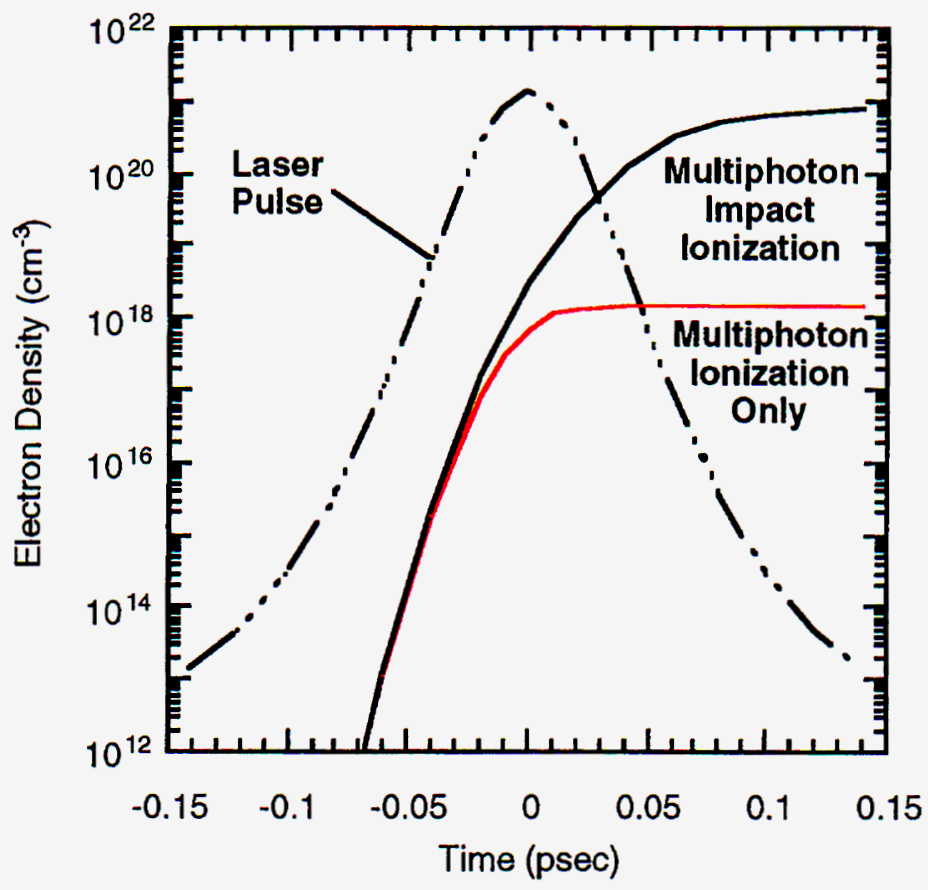

Figure 4. Calculated evolution of free electron density for a 100 -fs, $1053-\mathrm{nm}$ pulse (dashed curve) of peak irradiance $=10 \mathrm{TW} / \mathrm{cm}^{2}$ in fused silica. The total electron density including impact ionization and that due to multiphoton ionization alone are shown for comparison.

of a dielectric. It is now a conductor and will absorb the laser via inverse Bremstrahlung (Joule) heating similar to a metal. It is for this reason that both dielectrics and metals have similar behavior and morphology when machined with ultrashort pulses. In essence, the dielectric is converted to a metallic state within the first few tens of femtoseconds. As the laser intensity decreases past the peak of the pulse, the driving force for both multiphoton and collisional ionization ceases and the free electron density remains constant.

For laser pulses of different duration, the relative fraction of multiphoton ionization to avalanche ionization will change. Multiphoton ionization will contribute a relatively greater fraction of the electron density with shorter pulses while avalanche ionization will dominate with longer pulses. In all cases, the electron density saturates at the critical density, $\mathbf{N}_{c}$. The critical density is the density at which the plasma frequency, $\omega_{\text {pe }}(\mathrm{rad} / \mathrm{sec})=\left(4 \pi \mathrm{N}_{\mathrm{e}} \mathrm{e}^{2} / \mathrm{m}\right)^{1 / 2}=\left[2.21 \times 10^{8}\right.$ $\left.\mathrm{N}_{\mathrm{e}}\left(\mathrm{cm}^{-3}\right)\right]^{1 / 2}$ is equal to the laser frequency, $\omega=2 \pi \mathrm{c} / \lambda$. The critical density may be written as, $\mathrm{N}_{\mathrm{c}}$ $=\left(\pi \mathrm{m}_{\mathrm{e}} \mathrm{c}^{2} / \mathrm{e}^{2} \lambda^{2}\right)$. At a laser wavelength of $1064 \mathrm{~nm}, \mathrm{~N}_{\mathrm{c}}=0.98 \times 10^{21} \mathrm{~cm}^{-3}$. Note that the ratio $\mathrm{N}_{\mathrm{e}} \mathrm{l}$ $\mathrm{N}_{\mathrm{c}}=\omega_{\mathrm{pe}}^{2 /} \mathrm{c}^{\circ}$. The critical density plays an extremely important role in the interaction of electromagnetic waves with plasmas. This can best be illustrated by considering the dielectric function of the plasma, 


$$
\varepsilon(\omega)=1-N_{e} \frac{\langle\sigma\rangle}{\omega}\left(i+\omega \tau_{m}\right)=1-\frac{\omega_{p e}^{2}}{\omega\left(\omega+i v_{m}\right)}
$$

The dielectric function determines both the refractive index of the plasma and absorption of electromagnetic waves within the plasma. The transmission of an electromagnetic wave is given by the Fresnel relation,

$$
T=\left|\frac{2 \operatorname{Re} \sqrt{\varepsilon}(\omega)}{1+\sqrt{\varepsilon}(\omega)}\right|
$$

At critical density, the dielectric function becomes $\varepsilon_{\mathrm{cr}}(\omega)=1-1 /(1+\mathrm{iv} / \omega)$. Since $v / \omega \ll 1$ for all but the most collisional plasmas, $\varepsilon_{c r}(\omega) \approx 0$, and $T \approx 0$. Hence, once the electron density reaches the critical value, very little electromagnetic energy is transmitted.

Formation of a critical density plasma has an important effect in materials processing with short pulse lasers. Once the critical surface is formed, laser energy is either absorbed at that surface or reflected from it. For most plasmas, there is strong absorption at the critical surface since the scale length, $\mathrm{L}$, is equal to or greater than the wavelength of the incident light, $\mathrm{L}>\lambda .20$ Now, the maximum scale length is $\mathrm{L}_{\max }=\mathrm{v}_{s} \tau_{\mathrm{p}}$ where the ion sound velocity, $\mathrm{v}_{\mathrm{s}}=\left(\mathrm{ZkT}_{\mathrm{e}} / \mathrm{m}_{\mathrm{ion}}\right)^{1 / 2}$ $\approx 6 \times 10^{5} \mathrm{~cm} / \mathrm{sec}$. Since the pulses of interest here are $<10 \mathrm{ps}$, the maximum scale length is $\mathrm{L}_{\max } \approx 0.1 \mu \mathrm{m}$, which is much less than the incident wavelength. In the limit that $\mathrm{L}<<\lambda$, electromagnetic waves are reflected from the critical surface and not absorbed. In Figure 5, we show the reflectivity of a normally transparent fused silica surface as a function of incident laser intensity. Near the damage threshold $\left(\approx 10^{13} \mathrm{~W} / \mathrm{cm}^{2}\right)$, critical density is not produced until late in the pulse (Figure 4). Only the last part of the laser pulse will experience any strong reflection. However, by operating high above threshold, critical density is achieved early in the pulse and reflectivities exceeding $90 \%$ can be obtained. By measuring the phasefront of the reflected waves, the researchers showed that the maximum scale-length in the plasma was $<0.1 \lambda .{ }^{21}$

The damage threshold of fused silica calculated according to the plasma model just described is compared to measured damage thresholds at both $526 \mathrm{~nm}$ and $1053 \mathrm{~nm}$ from $10 \mathrm{fs}$ to over 10 ps in Figure 6. The theoretical damage fluence defining damage as the point at which the free electron density reaches the plasma critical density $\left(\approx 10^{21} \mathrm{~cm}^{-3}\right)$ is calculated with no adjustable parameters (Fig. 6, solid lines). Due to the rapid avalanche following production of the seed electrons by multiphoton ionization, the predicted damage threshold is only weakly dependent upon the actual free electron density at which damage occurs. A lower limit would correspond to the condition that the energy density of the conduction electrons equals the binding energy of the lattice $\left(\approx 10^{19} \mathrm{~cm}^{-3}\right)$. Use of this lower limit serves only to reduce the predicted damage threshold by $\approx 20 \%$. In addition to the good agreement with the measurements presented here, experiments 


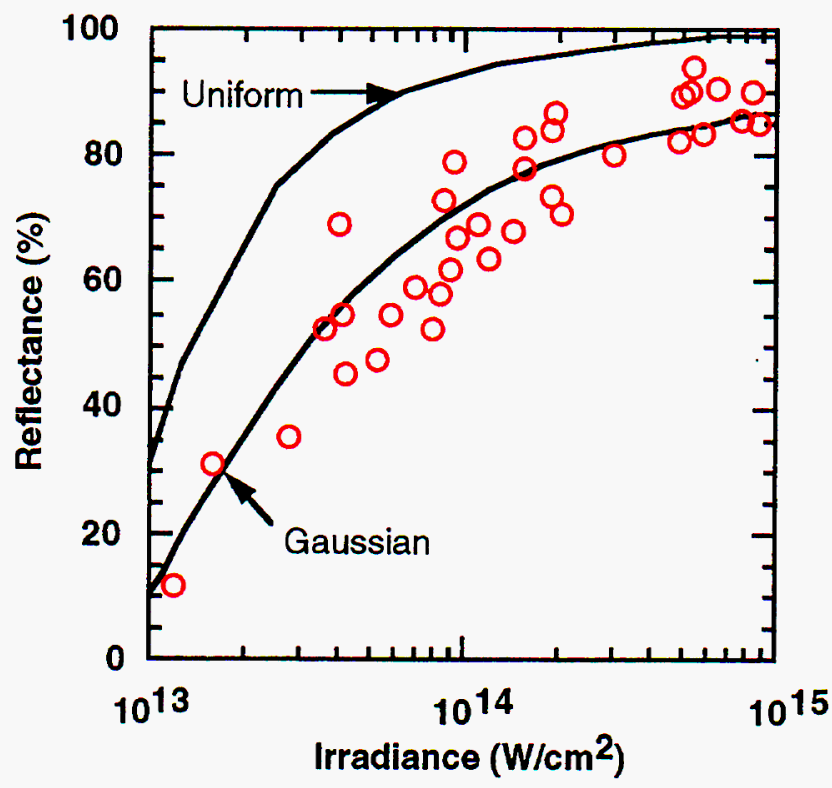

Figure 5. Reflectivity of fused silica surface as a function of laser irradiance for $\lambda=1053$ $\mathrm{nm}$ and $\tau_{\mathrm{p}}=350 \mathrm{fs}$. Calculated reflectivities using the model described in the text for a gaussian and uniform beam are shown for comparision.

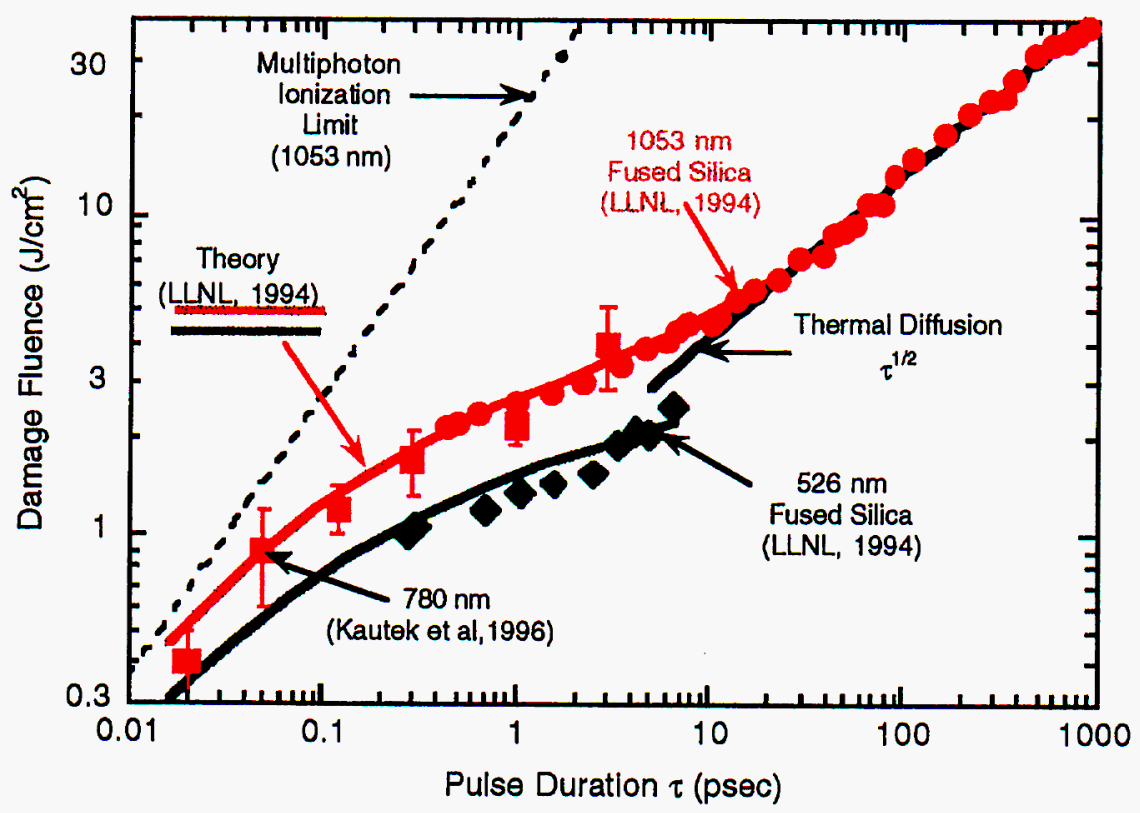

Figure 6. Measured and calculated damage thresholds of fused silica in the infrared and visible $(526 \mathrm{~nm})$. Deviation from $\tau^{1 / 2}$ scaling below $\approx 10 \mathrm{ps}$ indicates the transition to an ionization dominated damage mechanism. The calculated threshold for ablation by multiphoton ionization alone is shown as the dashed line. Data is taken from refs. 9 and 26. 
by Auderbert, ${ }^{22}$ von der Linde, ${ }^{23}$ Kautek, ${ }^{24}$ and Kraucsz, ${ }^{25}$ are also in good agreement with our calculations but not those of $\mathrm{Du}^{26}$. For pulses less than $100 \mathrm{fs}$, the predicted damage threshold asymptotically approaches the multiphoton limit. In the long-pulse regime ( $\tau>20 \mathrm{ps})$, the data fit well to a $\tau^{1 / 2}$ dependence, characteristic of transfer of electron kinetic energy to the lattice and diffusion during the pulse. The damage is thermal in nature and characterized by melting and boiling of the surface. For long pulses, heating of the lattice and subsequent thermal damage can occur without significant collisional ionization. ${ }^{13}$

A significant feature of this non-thermal material removal mechanism is that since there is minimal energy deposition in the remaining material, there is a minimal increase in temperature. Thermal measurements show that when irradiated with conventional nanosecond laser pulses, the bulk temperature of a $1-\mathrm{mm}$ slice of tooth increased by over $40^{\circ} \mathrm{C}$ while for femtosecond pulses the temperature rise was less than $2^{\circ} \mathrm{C}$ (Figure 7). The fluence in each case was set to remove approximately $1-\mu \mathrm{m}$ depth of material per pulse. This required $30 \mathrm{~J} / \mathrm{cm}^{2}$ for the nsec pulses and only $3 \mathrm{~J} / \mathrm{cm}^{2}$ for the femtosecond pulses. The practical consequences in dentistry are substantial. In the case of existing laser systems, active cooling of the tooth is necessary to prevent permanent damage to the pulp and nerves, which occurs at an increase of $\approx 5^{\circ} \mathrm{C}$ over body temperature. With ultrashort laser pulses, no cooling would be necessary.

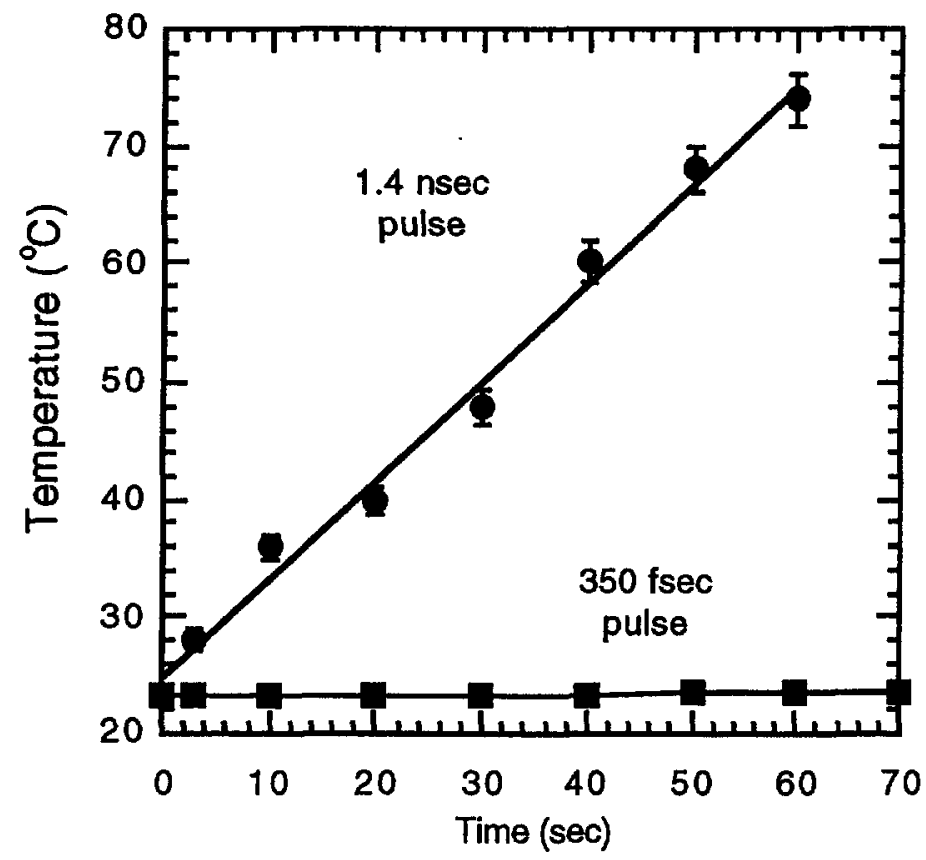

Figure 7. Temperature increase of bulk tooth due to drilling with 1.4-nanosecond (circles) and 350-femtosecond (squares) laser pulses. In both cases, the laser wavelength was 1053 $\mathrm{nm}$, and the spot size was $\mathbf{3 0 0} \mu \mathrm{m}$. The fluence was adjusted to achieve a material removal rate of $1 \mu \mathrm{m} /$ pulse at $10 \mathrm{~Hz}$ for both pulse durations. 
Another dramatic example is the machining of explosives with ultrashort laser pulses. Cutting and machining operations on energetic materials present significant safety challenges. With conventional machine tools, improper fixturing of the work, improper tuol configuration, and improper cutting speeds have resulted in violent reactions during machining operations. Conventional laser pulses are often used to ignite explosives. However, with femtosecond pulses, plasma formation and material removal occur too fast for significant energy transfer to the remaining material. Furthermore, since only a small amount of material is removed per laser pulse $(\approx 3 \mu \mathrm{m})$, there is negligible shock imparted to the remaining material. The shock wave that does exist decays to an insignificant level within $\approx 1 \mu \mathrm{m}$ of the surface. The waste products from short-pulse laser cutting are, for the most part, solid carbon or benign gases, which can be released into the atmosphere.

We have machined a variety of high explosives including LX-14 (95.5\% HMX/4.5\% Estane), LX-15 (95\% HNS/5\% Kel-F), LX-16 (96\%PETN/4\%FPC 461), LX-17 (92.5\% TATB/7.5\% Kel-F), PBX-9407 (94\% RDX/6\% Exon 461), and pressed TNT. In some of the experiments the beam first cut through the $\mathrm{HE}$ and then into a stainless steel substrate and in other experiments the beam first cut through stainless steel and then into the HE. Figure 8 shows two cuts across a 1-cm-diameter, 2-mm-thick pellet made using a 1-kHz, 100-fs Ti:sapphire laser system. Fourier Transform Infrared Spectroscopy of the laser cut LX-16 surface showed no evidence of any chemical reaction products. The laser cut surface was chemically identical to the original LX-16 material. We also observed very high aspect ratio cuts and holes $(\approx 1000: 1)$ in high explosives. When we used pulses only modestly in the conventional regime (600 ps) deflagration of the LX-16 pellet was immediately observed (Figure 8b). Examination of the pellet afterward revealed that the edges of the cut were melted and contained a multitude of reaction products consistent with thermally induced ignition.
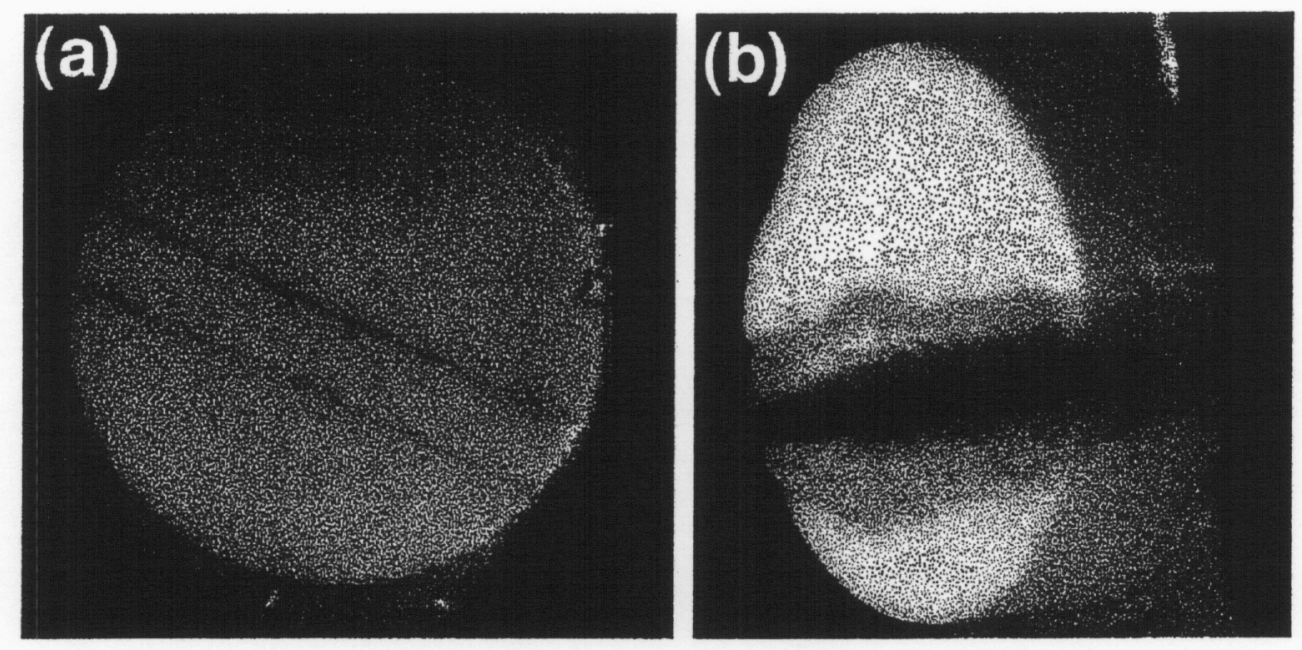

Figure 8. Cuts in explosive pellet (PETN) by a Ti:sapphire laser operating at $120 \mathrm{fs}$ (a) and $0.6 \mathrm{~ns}(\mathrm{~b})$. Thermal deposition in the long-pulse case caused the pellet to ignite. 
In summary for dielectric materials, there is a strong deviation from the usual $\tau^{1 / 2}$ scaling of laser damage fluence for pulses below $10 \mathrm{ps}$. The damage threshold continues to decrease with decreasing pulsewidth, but at a rate slower than $\tau^{1 / 2}$ in the range 0.1 to $10 \mathrm{ps}$. As the pulses become shorter than $\approx 0.1 \mathrm{ps}$, the increasing influence of multiphoton ionization results in a rapid decrease of the damage threshold. Multiphoton ionization provides an upper limit to the damage fluence for short pulses, preventing any increase in damage threshold with decreasing pulse duration as might be predicted from a pure avalanche model. This new mechanism of damage (material removal) is accompanied by a qualitative change in the morphology of the interaction site. The damage site is limited to only a small region where the laser intensity is sufficient to produce a plasma with essentially no collateral damage. This process enables high-precision machining of all dielectrics with no thermal shock or distortion of the remaining material. Although the absolute damage fluence varies, all pure dielectrics (oxides, fluorides, explosives, plastics, glasses, ceramics, etc.) exhibit similar behavior. All dielectrics share the same general properties of slow thermal diffusion and an electron-phonon scattering rate slower than the rate at which energy is absorbed from the field by the free electrons. All dielectrics should therefore exhibit similar short-pulse machining characteristics.

\section{Metals}

Metals are machined either with abrasive techniques (lathes, saws, drills), or by localized thermal processing (conventional lasers, electron beam, plasma or acetylene torch, etc.). The basic interaction in localized thermal processing is the deposition of energy from the incident beam in the material of interest in the form of heat (lattice vibrations). In the case of the laser, the absorption of energy is dependent upon the optical properties of the metal. The laser energy that is absorbed results in a temperature increase at and near the absorption site. The magnitude and spatial extent of the temperature achieved during the laser pulse is strongly dependent upon the thermomechanical properties of the metal. As the temperature increases to the melting or boiling point, material is removed by conventional melting or vaporization. ${ }^{27}$ Depending on the pulse duration of the laser, the temperature rise in the irradiated zone may be very fast, resulting in thermal ablation and shock. The irradiated zone may be vaporized or simply ablate off due to the fact that the local thermal stress has become larger than the yield strength (thermal shock). Plasma formation may even result in the vaporized plume. In all these cases, there is an impact on the material surrounding the site where material has been removed. The surrounding material will have experienced a large temperature excursion or shock often resulting in significant change to the material properties. These changes may range from a change in grain structure to an actual change in composition. Such compositional changes include oxidation (if cut in air) or, in the case of alloys, changes in composition of the alloy. This heat affected zone may range from a few microns to millimeters depending on the thermomechanical properties of the metal, laser pulse duration and other factors (e.g., active cooling). In many applications, the presence of the heat or shock effected zone may be severely limiting since the material properties of this zone may be quite different than that of the bulk. Furthermore, small-scale devices (features on the order of a few tens of microns) cannot tolerate the thermal stress induced in the material during the machining process. 
Another limitation of conventional laser or electron beam processing in certain applications is the lack of precision and the presence of redeposited or resolidified material. As mentioned previously, cutting or drilling occurs by either melting or vaporizing the material of interest. The surface adjacent to the removed area will have experienced significant thermal loading, often resulting in melting. This melting can be accompanied by flow prior to solidification. This can result in the deposition of slag surrounding the kerf (Figure 9a) which, in many high-precision applications, is unacceptable. Also, the resolidification process is not uniform, resulting in a lack of precision in the machined surface. In the cases where the deposition of conventional slag can be prevented, redeposition of vaporized material on the walls or upper surface of the kerf is common. This condensate often reduces the quality of the cut and decreases the cutting efficiency since the beam must again remove this condensate before interacting with the bulk


Figure 9. Cuts in stainless steel performed with $1054 \mathrm{~nm}$ laser pulses with a duration of (a) $1.4 \mathrm{~ns}$ at a fluence of $52 \mathrm{~J} / \mathrm{cm}^{2}$ and (b) $350 \mathrm{fs}$ and $14 \mathrm{~J} / \mathrm{cm}^{2}$. The fluence was adjusted to achieve a material removal rate of $0.5 \mu \mathrm{m} /$ pulse in both cases. 
material underneath. Many of these limitations can be reduced by the use of secondary techniques to aid the cutting process. The most common of these are active cooling of the material of interest either during or immediately following the laser pulse, and the use of high pressure gas jets to remove vaporized or molten material from the vicinity of the cut. These techniques can be effective at improving the kerf at the cost of an increase in system complexity and often a decrease in cutting efficiency.

As in the case of dielectrics, ultrashort pulses enable the laser cutting/machining of metals and alloys with high machining speed, extreme precision, negligible heat affected zone, and no modification to the material surrounding the kerf. Unlike dielectrics however, there is no multiphoton ionization step necessary since the metal already contains "free" electrons in the conduction band. These electrons will absorb the laser light via inverse Bremstrahlung heating (collisional absorption) as described previously. Again, a Fokker-Planck equation can be established to describe the energy transfer from the electrons to the lattice (electron-phonon coupling) and heat transfer directly by electron conduction away from the absorption site. Historically, this situation has been described by a simple two temperature model for the ion and electron temperatures. ${ }^{28}$ Since on the time scales of interest, the temperature gradients in transverse dimensions are negligible relative to that in the longitudinal dimension, a onedimensional description is adequate:

$$
C_{e} \frac{\partial T_{e}}{\partial t}=\frac{\partial}{\partial z}\left(k \frac{\partial T_{e}}{\partial z}\right)-\gamma\left(T_{e}-T_{i}\right)+A(z, t)
$$

and

$$
\mathrm{C}_{\mathrm{i}} \frac{\partial \mathrm{T}_{\mathrm{i}}}{\partial \mathrm{t}}=\gamma\left(\mathrm{T}_{\mathrm{e}}-\mathrm{Ti}\right)
$$

where $C_{e}$ and $C_{i}$ are the heat capacity of the electrons and ions (lattice) respectively, $\gamma$ is the rate that electron energy is dissipated to the lattice via phonons $\left(\mathrm{W} / \mathrm{cm}^{3}-{ }^{\circ} \mathrm{K}\right)$, and $\mathrm{A}(\mathrm{z}, \mathrm{t})$ is the source term. Since the conductivity of the lattice is much lower than the electron-phonon transfer rate, $k_{i}<<\gamma$, the term representing conduction through the lattice has been neglected in (eq. 15). Since the time scale for energy transfer from the electrons to the lattice via phonon scattering is finite, short laser pulses can heat the electrons to high temperatures with very little energy transfer to the ions (lattice). Hence, the need for a two temperature description. For a simple metal, the electron heat capacity and conductivity are described by the Fermi relations,

$$
\mathrm{C}_{\mathrm{e}} \approx \frac{\pi^{2}}{2}\left(\frac{k \mathrm{~T}_{\mathrm{e}}}{E_{F}}\right) \mathrm{N}_{\mathrm{e}} k \text { and } \mathrm{k}_{\mathrm{e}}=\frac{2}{3} \frac{E_{F}}{\mathrm{~m}_{\mathrm{e}} v} \mathrm{C}_{\mathrm{e}}
$$

where $E_{F}$ is the Fermi energy $(\approx 7 \mathrm{eV})$ and $v=v_{\mathrm{ee}}+v_{\mathrm{ei}}$ is the sum of the electron-electron collision frequency $v_{e e}$ and the electron-lattice (ion) collision frequency, $v_{e i}$. In the limit that $\psi>\infty, T_{e}=T_{i}$ $\Rightarrow \mathrm{T}$ and eq. 14 reduces to the usual one-dimensional heat conduction equation for the temperature, T. Simplified versions of these eqs. 14,15 have been solved analytically and provide good insight into the important physical processes. ${ }^{29}$ 
A solution of these equations in the limit of fast equilibration between the ions and electrons for gold irradiated at $1053 \mathrm{~nm}$ and $0.5 \mathrm{~J} / \mathrm{cm}^{2}$ is given in Figure 10. The thermal penetration depth achieved during the pulse, $L_{t h}=2 \sqrt{ } \alpha \tau$, is less than one micron resulting in a very small amount of material (0.01-1 micron) heated to above the boiling point with extremely small transport of energy either by shock or thermal conduction away from the volume of interest. For pulses with a duration below the characteristic energy transfer time between electrons and the lattice, the model described by eqs. 14 and 15 predicts a damage threshold which no longer scales as $\tau^{1 / 2}$ as is predicted by a conventional thermal mechanism of damage. Instead, the damage threshold is predicted to be essentially independent of pulse duration. ${ }^{30}$ This behavior is observed in all metals which we have investigated. In Figure 11, we show the damage threshold of gold measured at $1053 \mathrm{~nm} .^{31}$ The essential constancy of the damage threshold below $\approx 80 \mathrm{ps}$ is readily observed and the data is well fit by the two temperature model with $\gamma=3.5 \times 10^{11}$ $\mathrm{W} / \mathrm{cm}^{3}-^{\circ} \mathrm{K}$.

For real machining applications, the surface of the metal is heated far beyond its boiling point and the simple two temperature model breaks down. Instead, a full radiative hydrodynamic model is required that accounts for plasma formation, multiple ionization, material equation of state and shock wave generation and cooling by radiation, conduction and plasma expansion (PdV work). A one-dimensional Euler-Lagrangian code was developed for this purpose. ${ }^{32}$ The predicted pressure and temperature of aluminum irradiated in the ultrashort-pulse regime (350 fs) and the conventional (ns) regime are given in Figures 12-14. For the femtosecond pulse focused

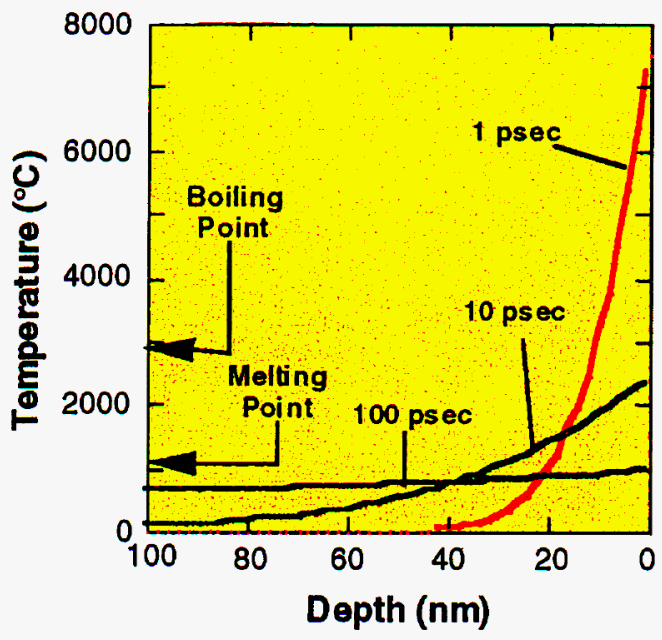

Figure 10. Calculated temperature profiles in gold irradiated at $1054 \mathrm{~nm}$ and a fluence of $0.5 \mathrm{~J} / \mathrm{cm}^{2}$ for 1,10 , and 100 ps pulses. 


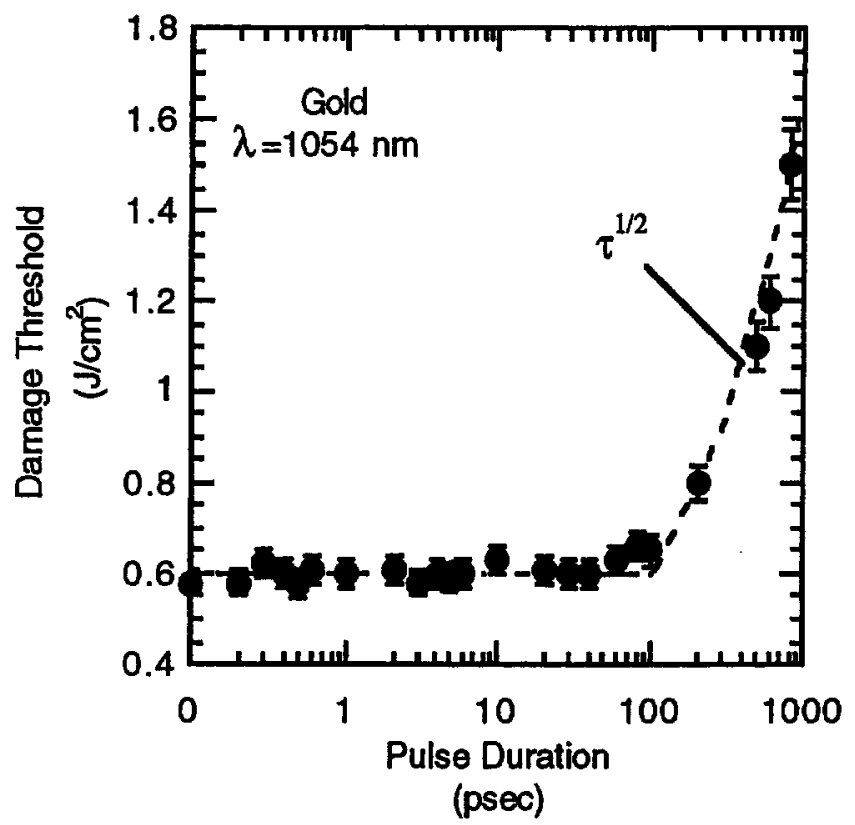

Figure 11. Damage threshold of gold at $1054 \mathrm{~nm}$ as a function of pulse duration [from ref. 29]

to $5 \mathrm{~J} / \mathrm{cm}^{2}\left(1.4 \times 10^{13} \mathrm{~W} / \mathrm{cm}^{2}\right)$, the absorbed laser energy heats the skin depth of the material to $\approx 12.5 \mathrm{eV}$ (Figure 12b). In the next few picoseconds, this energy is dissipated into the bulk by both shock and electron conduction and is also dissipated by the initial plasma expansion off the surface and radiation. A depth of $\approx 0.1$ micron is heated to near $1 \mathrm{eV}$. This material blows off the surface with a static expansion velocity of $2 \times 10^{6} \mathrm{~cm} / \mathrm{s}$ over the next nanosecond (Figure 13b). Note that the solid left behind remains essentially at room temperature even within $\approx 1 \mu \mathrm{m}$ of the machined surface. The initial shock wave launched into the material is large reaching $2 \mathrm{Mbar}$. This shock propagates with a velocity $=6 \times 10^{5} \mathrm{~cm} / \mathrm{s}$ but dissipates rapidly in magnitude. The pressure associated with the shock drops to less than $100 \mathrm{kbar}$ (less than the yield strength of the material) within the first micron (Figure 13). This offers extremely high-precision machining with no heat or shock effected zone extending beyond $\approx 1 \mu \mathrm{m}$ of the machined surface. In the case of a 1-ns pulse, the majority of the laser energy is absorbed in the expanding plasma. The energy that strikes the surface heats a depth of $\approx 2 \mu \mathrm{m}$ to the boiling point and a few microns to the melting point (Figure 14). For the even longer pulses more typical of laser machining, the temperatures achieved are below the ionization threshold and standard thermal models (which only account for melting and boiling) are adequate.

The lack of significant energy deposition beyond the volume of interest achieved by using ultrashort pulses enables the use of high repetition $(0.1-100 \mathrm{kHz})$ lasers without the need for external cooling of the part being machined. Even though only a very small depth of material is removed per pulse, the high repetition rate enables extremely high cut rates (beyond $1 \mathrm{~mm}$ depth per second). Another feature of the very short pulse duration is the fact that there is no vaporiza- 
tion or transport of material during the pulse (Figure 12). During the pulse, there is insufficient time for hydrodynamic expansion of the vaporized material. As a result, the laser encounters the solid surface for the duration of the pulse depositing energy into solid density material.
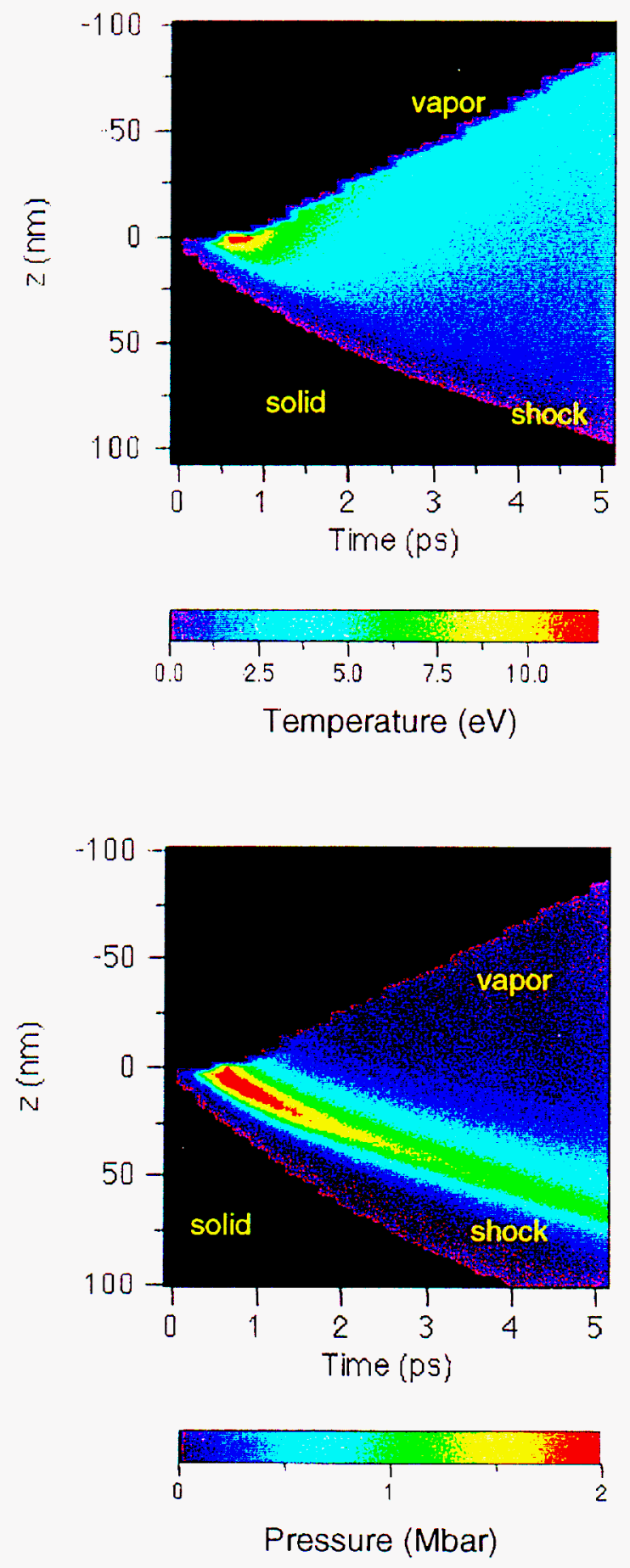

Figure 12. Calculated temperature (a) and pressure (b) of aluminum irradiated by 1053 $\mathrm{nm}, 350$-fs laser pulses at a fluence of $5 \mathrm{~J} / \mathrm{cm}^{2}$. 

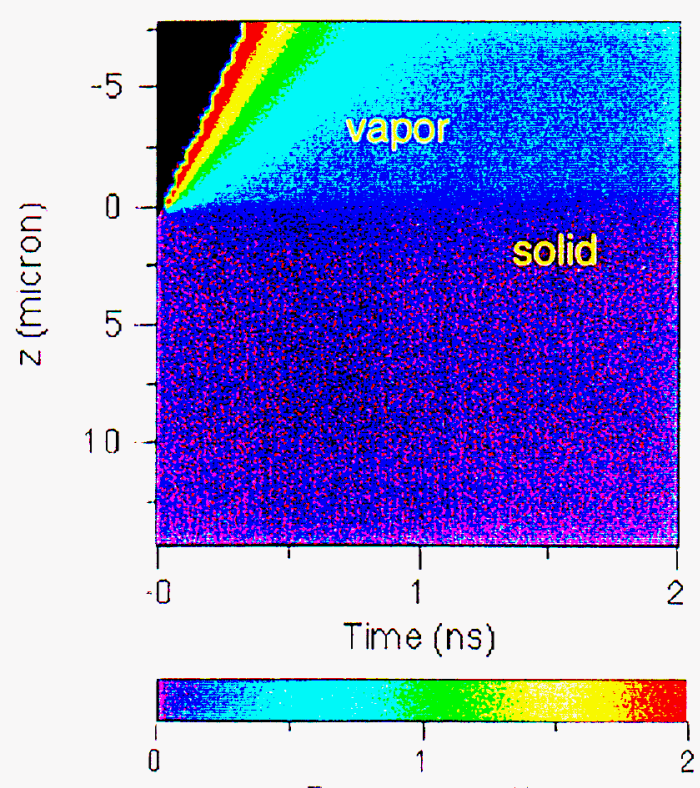

Temperature (eV)

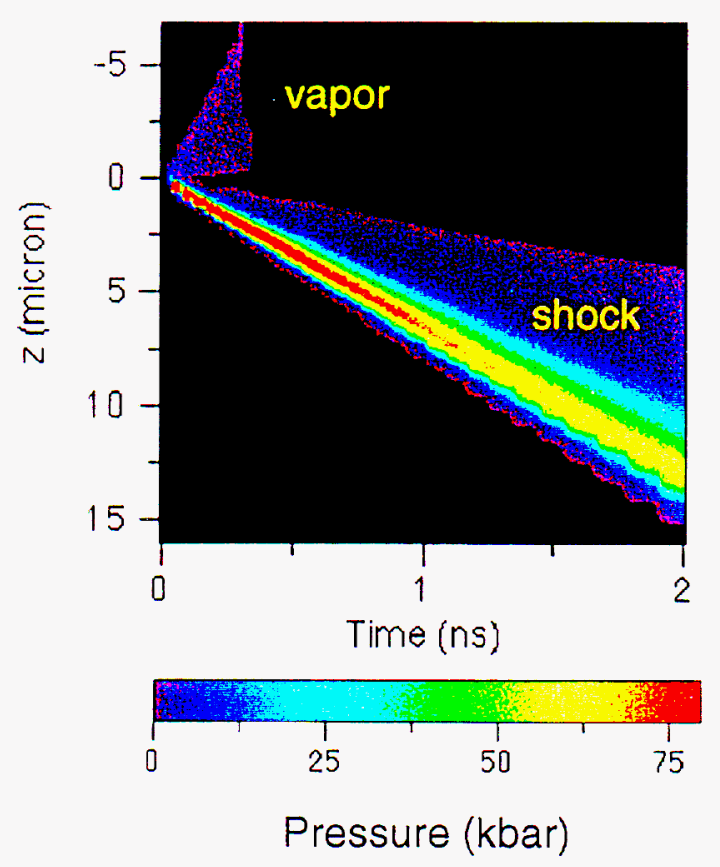

Figure 13. Calculated temperature (a) and pressure (b) of aluminum following irradiation by $1053-\mathrm{nm}, 350-\mathrm{fs}$ laser pulses at a fluence of $5 \mathrm{~J} / \mathrm{cm}^{2}$. The calculation is carried out to two nanoseconds showing plasma blowoff and decay of the shock wave. 

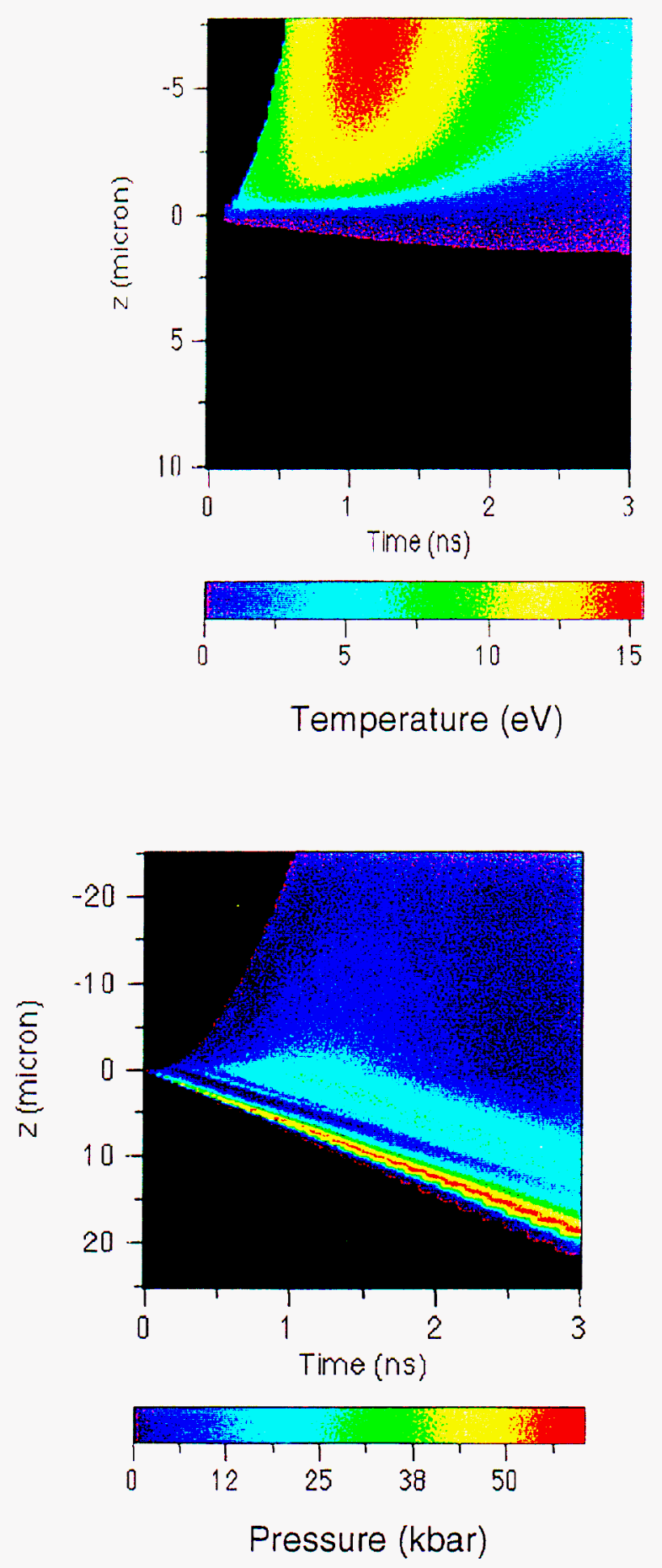

Figure 14. Calculated temperature (a) and pressure (b) of aluminum following irradiation by a 1053-nm, 1-ns laser pulse at a fluence of $20 \mathrm{~J} / \mathrm{cm}^{2}$ (same depth of material removed as in Figure 13). 
While the typical temperatures achieved at the damage threshold may be only a fraction of an electron volt $\left(1000-3000^{\circ} \mathrm{K}\right)$, those achieved for useful machining are between 1 and $100 \mathrm{eV}$. The temperature is determined by the product of the incident laser irradiance, $I\left(W / \mathrm{cm}^{2}\right)$, the square of the laser wavelength, $\lambda^{2}(\mu \mathrm{m})$, and the absorption characteristics of the metal. The difference between the threshold and the fluence required for useful machining is illustrated for stainless steel in Figure 15. At threshold, only a very small amount of material $(<0.1 \mu \mathrm{m})$ is removed per laser pulse. As the laser fluence is increased, the depth of material removed increases rapidly and then saturates at $\approx 12 \mathrm{~J} / \mathrm{cm}^{2}$. For the $120-\mathrm{fs}$ pulses used in these experiments, the peak irradiance was over $10^{14} \mathrm{~W} / \mathrm{cm}^{2}$ and produced an initial plasma temperature near $20 \mathrm{eV}$.

The high plasma temperatures associated with saturated material removal ensure that the vaporized material will be completely removed from the kerf without redeposition on the walls. For example, an expanding vapor with even a low expansion velocity of $10^{5} \mathrm{~cm} / \mathrm{sec}$ will be 1 meter away from the surface before the arrival of the next pulse $1 \mathrm{~ms}$ later (operating at $1 \mathrm{kHz}$ ). With conventional nanosecond or microsecond lasers, the vapor will evolve during the laser pulse (Figure 14). This reduces the coupling of the laser light to the solid surface since the incident laser light will be scattered and absorbed by the vapor.

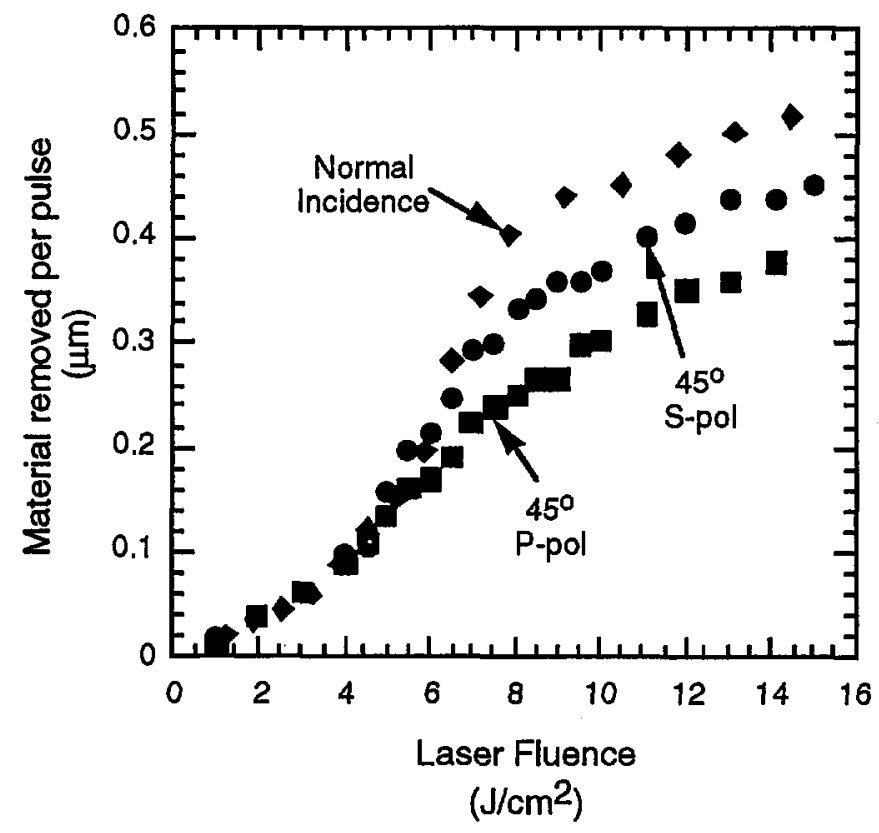

Figure 15. Depth of material removed per laser pulse for stainless steel and $\lambda=825 \mathrm{~nm}$. 
The cross-section of a $400-\mu \mathrm{m}$ hole in $0.8-\mathrm{mm}$-thick stainless steel drilled at $45^{\circ}$ with 120 -fs pulses shows that metallic grain structure is unaltered up to the edge of the hole (Figure 16). High resolution microscopy indicates that there is no heat or shock affected zone extending beyond $\approx 1 \mu \mathrm{m}$ away from the surface. The top (entrance) and bottom of the hole are typical of holes drilled with pulses having a Gaussian spatial profile. The shape of the hole is deterministic with no evidence of slag or heat-affected zone. Material is removed only in those regions where the beam intensity is sufficient to form a plasma. This deterministic nature of material removal makes possible the production of shaped cuts, holes or textured surfaces by shaping the spatial profile of the laser beam. Several researchers have used diffractive optics to modify the spatial profile of the beam to produce holes, with very steep side walls. ${ }^{33,34}$ A shaped fuel injector nozzle produced with 120 -fs pulses and a diffractive phase plate to produce a nearly flat top, 0.2 $\mathrm{mm}$-diameter beam is shown in Figure 17.

High-aspect-ratio holes and cuts $(0.05-\mathrm{mm}$ diameter thru $1.0 \mathrm{~mm}$ ) have been produced in numerous metals and dielectrics. Production of high-aspect-ratio features requires consideration of the waveguide nature of the feature and associated beam shaping. Tailoring the beam to avoid possible condensation of the plasma plume on the walls must also be considered for the production of high aspect ( $>8: 1$ ) ratio features. Analysis of these issues is beyond the scope of this paper.

\section{Laser Technology}

The depth of material removed at the optimum fluence with ultrashort-pulse lasers is limited to $\approx 0.5 \mu \mathrm{m}$ per laser pulse for both dielectrics and metals. Hence, the rate of material removal scales essentially linearly with the repetition rate of the laser system. Since the optimum fluence is fixed by the material to be machined and the aspect ratio of the feature of interest, the area which can be machined per laser pulse is set by the energy of the pulses. Combining these features, the volumetric machining rate scales linearly with the average power of the laser. Ultrashort-pulse lasers are based on the concept of chirped-pulse amplification described for lasers by Fisher and Bischel. ${ }^{35}$ This technique was first realized to produce picosecond pulses in a solid-state laser system by Strickland and Mourou. ${ }^{36,37}$ Since the first demonstration, dramatic improvements in laser architecture, laser materials and technology have led to compact systems producing terawatt and even petawatt pulses. ${ }^{38,39}$ These relatively high pulse energy systems are of limited use for machining applications. Instead, high repetition rate systems with only modest pulse energy 1-20 mJ are required. These systems are almost all based on Titanium-doped sapphire as the laser material. Commercial systems designed for scientific research are available at the $1-\mathrm{W}$ level $(1 \mathrm{~mJ}$ per pulse at $1 \mathrm{kHz}$ repetition rate) and $2-\mathrm{W}$ custom systems have been produced.

The first true machining system for use in industrial production was recently developed at Lawrence Livermore National Laboratory (Figure 18). The system is based on Ti:sapphire as the laser material and produces $1.5-\mathrm{mJ}$ pulses with a duration of 120 -fs and diffraction-limited beam quality. In order to achieve high machining speed, the repetition rate of the system is $10 \mathrm{kHz}$ 

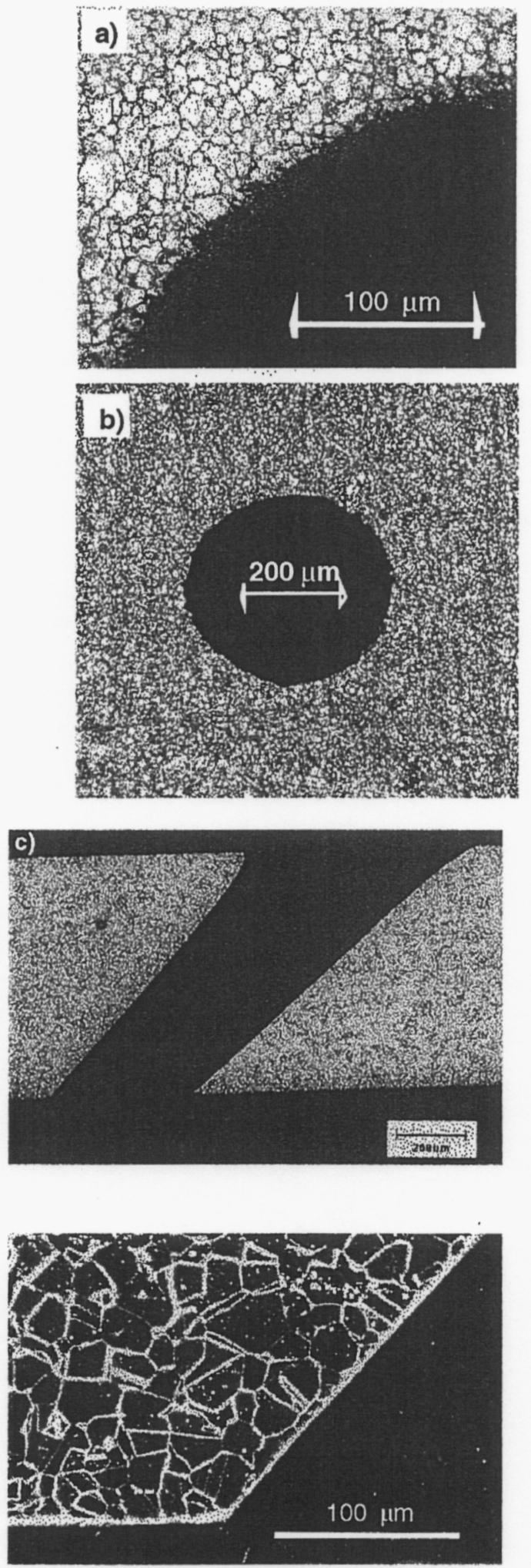

Figure 16. Holes drilled through $1 \mathrm{~mm}$ stainless steel with 120 -fs laser pulses at $1 \mathrm{kHz}$ at $4^{\circ}$. (a) Magnified section of top of hole, (b) exit hole on bottom, (c) cross section, (d) magnified (bottom left) section of cross section. 




Figure 17. Holes drilled through $1 \mathrm{~mm}$ stainless steel for fuel injector nozzles.

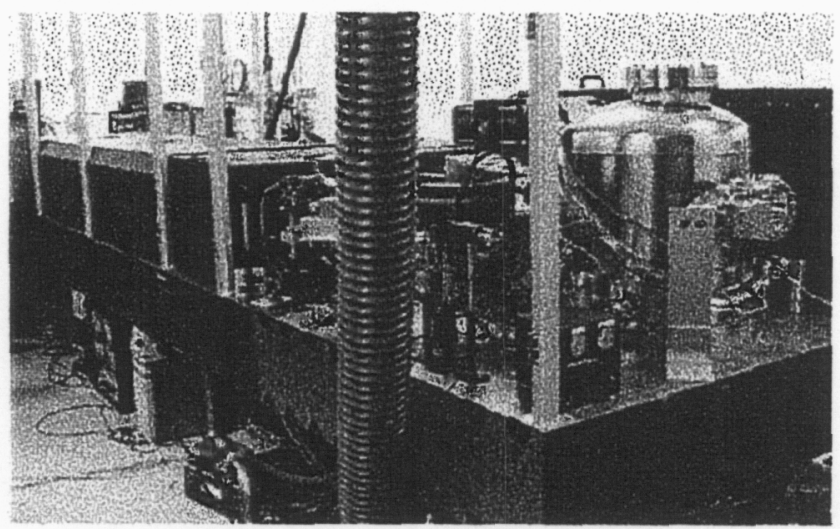

Figure 18. Photograph of a $15-W$ average power femtosecond laser machining system developed for industrial operation.

resulting in an average power of $15 \mathrm{~W}$. The system is fully computer-controlled and is designed to be operated by a machinist. The system is modular in design and completely self-contained. Individual modules can be removed and replaced on the line to minimize any down time for maintenance.

Although Ti:Sapphire based ultrashort-pulse lasers can be scaled in average power up to $\approx 100 \mathrm{~W}$, the complexity of these systems will limit their use. This complexity arises from the short upper-state lifetime ( $\tau \approx 2 \mu \mathrm{sec}$ ) of the laser material itself. The short energy storage time requires that the Ti:Sapphire be pumped by a second laser system. This laser-pumped laser requirement leads to a complex system where industrial quality standards of availability factor and ease of use will be difficult to achieve (particularly beyond the $\approx 20 \mathrm{~W}$ level). This complexity can be substantially reduced by the use of new laser materials which offer both broad-bandwidth (necessary to produce the short pulse) and a long upper-state lifetime enabling direct diode-pumping. Such systems offer the promise of kilowatt-class average power in a simplified, compact package. The first of these new direct diode-pumped systems is currently in development at LLNL. 


\section{Conclusion}

The use of ultrashort-pulse lasers allows materials processing of practically any material (diamond, $\mathrm{SiC}$, teeth, stainless steel, explosives, $\mathrm{TiC}$, etc.) with extremely high precision and minimal collateral damage. Advantages over conventional laser machining (using pulses longer than a few tens of picoseconds) are realized by depositing the laser energy into the electrons of the material on a time scale short compared to the transfer time of this energy to the bulk of the material (either by electron-phonon coupling or thermal diffusion). The process forms a critical density plasma, which then expands away from the surface following the laser pulse. High ablation efficiency is achieved with negligible energy deposition to the remaining material either by heat or shock. As a result, high-speed machining of materials to the micron scale can be realized. 


\section{Acknowledgements}

Ultrashort-pulse laser machining is now being developed at a variety of locations throughout the world. We would like to acknowledge other pioneering work in this field by P. Callen, E. Glenzer, W. Kautek, C. Momma, G. Mourou, and S. Nolte and thank them for many helpful discussions. We also thank P. Armstrong, N. Frank, B. Pyke, D. Shipley and others involved in the design and construction of the femtosecond machining system. This work was performed under the auspices of the U.S. Department of Energy by Lawrence Livermore National Laboratory under contract No. W-7405-ENG-48. 


\section{References}

1. S. C. Jones, P. Braunlich, R. T. Casper, X.-A. Shen, and P. Kelly, Opt. Eng. 28, 1039 (1989).

2. N. Bloembergen, IEEE J. Quantum Electron. QE-10, 375 (1974).

3. Laser Induced Damage in Optical Materials, Proceedings of the Boulder Damage Symposium: Vols. 1-25 (1969-93).

4. A.A. Manenkov and A.M. Prokhorov, Sov. Phys. Usp. 29, 107 (1986).

5. M. Sparks, D. L. Mills, R. Warren, T. Holstein, A. A. Maradudin, L. J. Sham, E. Loh Jr., and D. F. King, Phys. Rev. B 24, 3519 (1981).

6. R.M. Wood, Laser Damage in Optical Materials (Hilger, Boston, 1986).

7. J.H. Campbell, F. Rainer, M. Kozlowski, C.R. Wolfe, I. Thomas, and F. Milanovich, in Laser Induced Damage in Optical Materials, SPIE Vol. 1441, 444 (1990).

8. M.D. Perry and E.M.Campbell, Petawatt Laser Proposal, LLNL Internal Report (1992)

9. B.C. Stuart, M.D. Feit, A.M. Rubenchik, B.W. Shore, and M.D. Perry, Phys. Rev. Lett., 74, 2248 (1995).

10. D. Du, X. Liu, G. Korn, J. Squier and G. Mourou, Appl. Phys. Lett., 264, 917 (1994).

11. X.A. Shen, S.C. Jones, and P. Braunlich, Phys. Rev. Lett. 62, 2711 (1989).

12. L. H. Holway Jr. and D. W. Fradin, J. Appl. Phys. 46, 279 (1974).

13. D. Arnold, E. Cartier and D. J. DiMaria, Phys. Rev. A 45, 1477 (1992).

14. B. K. Ridley, Quantum Processes in Semiconductors (Clarendon, Oxford, 1993).

15. M. D. Perry and O. L. Landen, Physical Review A, 38, 2815(1988).

16. L.V. Keldysh, Sov. Phys., JETP 20, 1307 (1965).

17. M. D. Perry, A. Szoke, O. L. Landen, and E. M. Campbell, Phys. Rev. Lett. 60, 1270 (1988); ibid,Phys. Rev. A, 37, 747 (1988).

18. M.V. Ammosov, N.B. Delone, and V.P. Krainov, Sov. Phys., JETP, 64, 1191 (1986).

19. B.C. Stuart, M.D. Feit, S. Herman, A. Rubenchik, B.W. Shore and M.D. Perry, Phys. Rev. B, 53 (1996).

20. W.Kruer, Physics of Laser Plasma Interactions,

21. M.D. Perry, V. Yanovsky, A.M. Rubenchik and M.D. Feit, Plasma Mirrors, submitted to Physics of Plasmas, (1998).

22. P. Audebert, Ph. Daguzan, S. Guizard, K. Krastev, P. Martin, G. Petite, A. Dos Santos, and A. Antonetti, Phys. Rev. Lett., 73, 1990 (1994).

23. D. von der Linde and H, Schuler in Proceedings of Short Wavelength VI: Physics with High Intensity Pulses, St. Malo, France (1994).

24. W. Kautek, J. Kruger, M. Lenzner, S. Sartania, C. Spielmann, F. Krausz, Appl. Phys. Lett. 69, 3146 (1996).

25. F. Krausz, et al, Phys. Rev. Lett., to be published.

26. D. Du, X. Liu, J. Squier, and G. Mourou, Appl. Phys. Lett., 64, 3071, (1994).

27. J.F. Ready, Effects of High-Power Laser Radiation, Academic Press, New York, 1971.

28. S.I. Anisimov, B.L. Kapeliovich and T.L. Perlman, Sov. Phys. JETP, 39, 375 (1974).

29. S, Nolte, C. Momma, H. Jacobs, A. Tunnermann, B. Chichkov, B. Wellegehausen, and H. Welling, J. Opt. Soc. Amer. B, 14, 2716 (1997).

30. P.B. Corkum, F. Brunel, N.K. Sherman, and T. Srinivasan-Rao, Phys. Rev. Lett., 61, 2886 (1988).

31. M.D. Perry, et al, Conference on Lasers and Electrooptics, Baltimore May 1994; B. Stuart, S. Herman, M.D. Feit, B.W. Shore, and M.D. Perry, J. Opt. Soc. Amer. B, 13, 459 (1996).

32. A.M. Rubenchik, M.D. Feit, M.D. Perry and J.T. Larsen, App. Surface Science, 127, 193 (1998).

33. M.D. Perry, B.C. Stuart, H. Nguyen, M.D. Feit, and S. Dixit, OSA Annual Meeting, Portland (1996).

34. S. Nolte, C. Momma, et al, OSA Annual Meeting, Long Beach, CA (1997) 
35. R.A. Fisher and W. Bischel, "Pulse Compression for more efficient operation of solid-state laser amplifier chains, Appl. Phys. Lett., 24, 468 (1974); ibid,IEEE J. Quan. Elec., QE-11, 46 (1975).

36. D. Strickland and G. Mourou, Opt. Comm. 56, 219 (1985).

37. P. Maine, D. Strickland, P. Bado, M. Pessot, and G. Mourou, IEEE J. Quantum Electron. 24, 398 (1988).

38. M.D. Perry and G. Mourou, "Terawatt to Petawatt Lasers," Science 264, 917 (1994).

39. G. Mourou, C.P. Barty and M.D. Perry, Physics Today, p. 22, January (1998) 
Analysis by

Scanning

Femtosecond

Laser

Ultraprobing

A completely new approach to simultaneous analysis of the chemical-elemental, isotopic and molecular compositions of all types of material objects, in microscopic spatial resolution, CASFLU is an experimentally-demonstrated technology-package now available for licensing by production- and marketing-oriented industrial partners.

Leveraging the Lawrence Livermore National Laboratory's world-famous ultra-high power laser technology - just now becoming commercially-supported - CASFLU integrates state-of-the-art optical- and mass-spectral detectors into a revolutionary advance in material analytic capabilities, for the full spectrum of composition-analysis applications.

Under control of its PC-based computer sub-system, the CASFLU laser sub-system flashvaporizes microscopic mass-pixels of the object being analyzed so swiftly that these ablation events doesn't perturb the underlying material. Each tiny vapor-plume is then compositionally analyzed on-the-fly, with the results being stored into the growing 3-D map of the object's composition(s) in the computer's memory. Sustained, positionally-stepped repetition of this analytic dissection of the object yields its composition(s) as a function of $\{x, y, z\}$, with nearly any spatial resolution which may be required.

CASFLU analytic systems may also be employed to separate an object of any specified composition from material(s) of differing composition(s) in which it may be embedded.

\title{
ATTAINABLE SPATIAL RESOLUTION: $1 \mu \mathrm{m} \times 1 \mu \mathrm{m}$ (transverse) $\times 0.1 \mu \mathrm{m}$ (depth)
}

ISOTOPIC RANGE \& MASS-RESOLUTION: Mass spectrometric state-of-the-art

ATTAINABLE ANALYTIC RATE: $\leq 10^{8}$ mass-pixels/second

\author{
CHEMICAL-ELEMENTAL RANGE: All chemical elements
}

OBJECT COMPOSITION RESTRICTIONS: None

OBJECT SIZE/SHAPE LIMITATIONS: None

\footnotetext{
For further CASFLU technical information, contact Dr. Muriel Ishikawa, Univ. Calif. Lawrence Livermore Nat'l. Lab., L-491, P.O. Box 808, Livermore CA 94551 ; +925 4234178 [voice]; +925 4231243 [fax].

For CASFLU licensing information, contact the Industrial Partnerships and Commercialization Office, UCLLNL,

L-795, P.O. Box 808, Livermore CA $94551 ;+9254226416$ [voice]; +925 4238988 [fax].

Copyright 1999, University of California Lawrence Livermore National Laboratory. All rights reserved.
} 




Before and after microscope photographs of a 3-D copper mesh test pattern.

This demonstration of the High-Speed 3-D Object Composition Mapping

Technology (DOCMT) revealed extremely fine variation and warpage present in the test pattern. Data from several DOCMT layers are shown in the above figure. 


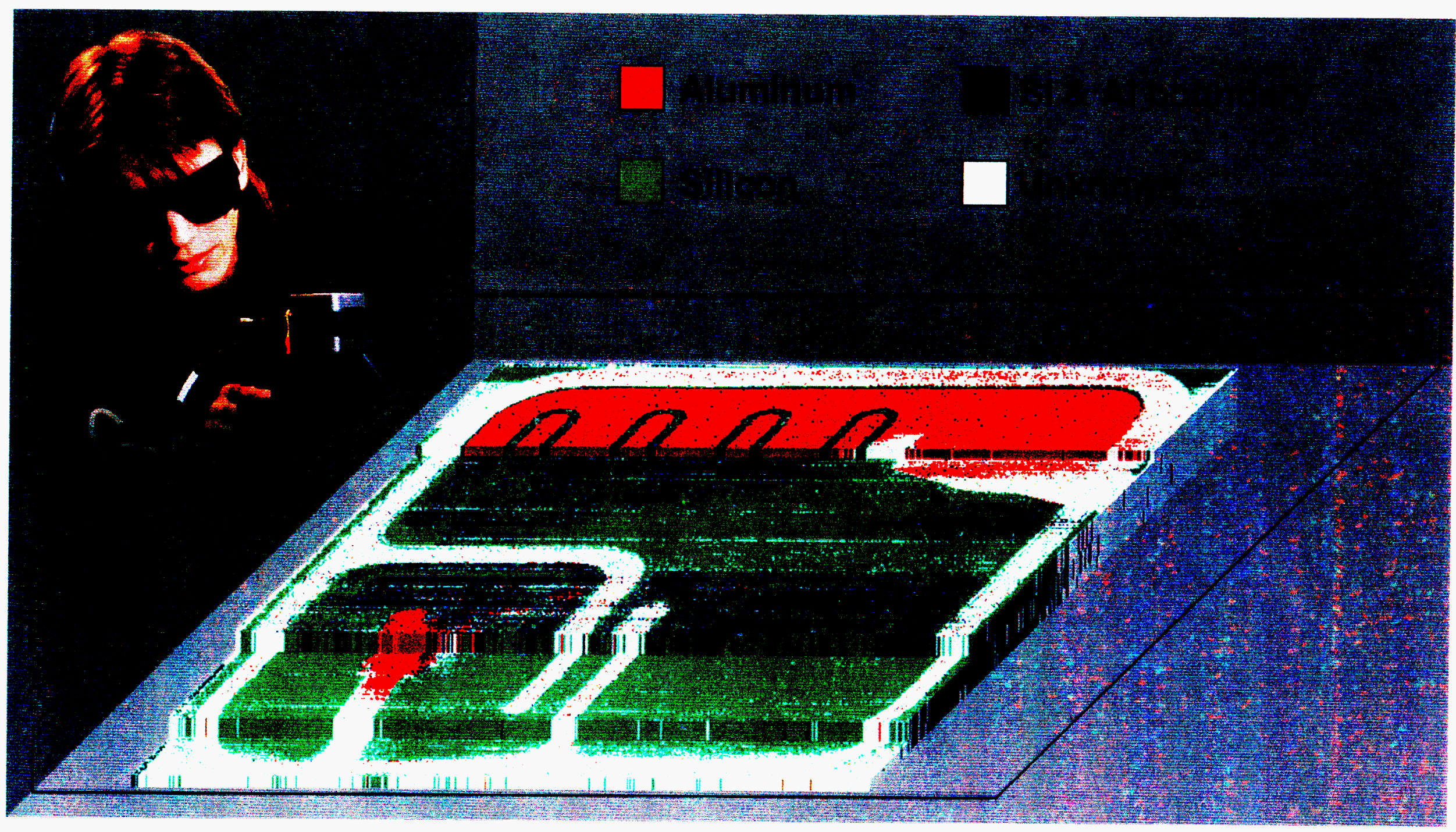

An example of the High-Speed 3-D Object Composition Mapping Technology as applied to a Si Darlington transistor circuit, before computer-based synthesis of the object's 3-D composition map. The distinctly different composition of the various horizontal layers of the transistor circuit, can be clearly seen in this cutaway. 


\section{the answer is \\ Mewsidentat}

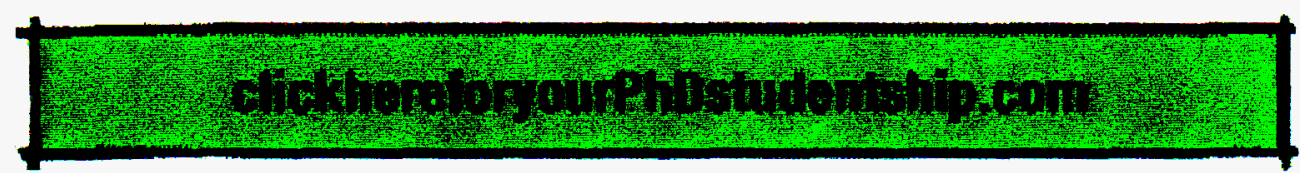

| home | subscribe | jobs |
NEWS $6 / 11 / 99$

This week's stories from New Scientist available online.

A false sense of security Computer prompts in the cockpit could make pilots more prone to error

Anyone can do it Savant skills may not be the sole preserve of autistic patients

A soft touch

Ever wondered why con artists find the elderly so easy to hoodwink?

\section{Morning story}

Early risers could be feeling the strain

Defence of the realm When it comes to arms control, logic can't compete with party politics and paranoia

Spying made simple Electronic eavesdropping is becoming child's play

Trouble in mind Depression? Too few new brain cells could be the cause

The bare bones

Why fossils will be getting the laser treatment

Sniff, sniff

Two nostrils are definitely better than one

Bald facts

A bit thin on top? Have a hair transplant

Too much too young? Today even two-year-olds are treated with behaviour drugs
Peeling away the past
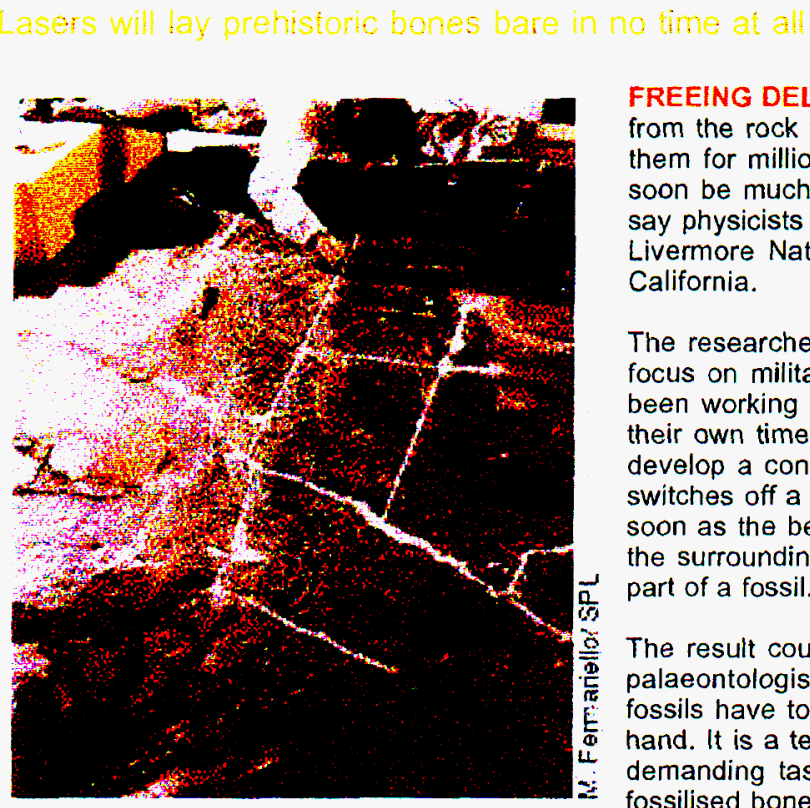

FREEING DELICATE FOSSILS from the rock that has entombed them for millions of years could soon be much easier and quicker, say physicists at the Lawrence Livermore National Laboratory in California.

The researchers, who normally focus on military projects, have been working on the project in their own time. The idea is to develop a control system that switches off a cutting laser as soon as the beam slices through the surrounding rock and touches part of a fossil.

The result could be a boon to palaeontologists. At the moment fossils have to be cleaned by hand. It is a tedious and demanding task, especially if the fossilised bones are softer than the surrounding rock. "Preparing a little mammal skull could take one to two months full time," says Pete Reser of the New Mexico Museum of Natural History, while complete dinosaurs can take up to 20 people-years.

The Livermore team uses powerful infrared laser pulses that last just 100 femtoseconds. The pulses are so short that the surface layer absorbs virtually all the energy and vaporises one micrometre at a time, leaving no excess heat behind to damage the underlying material

To tell what the laser is cutting through, the researchers monitor the emission spectrum of the vapour produced. "We diagnosed in real time the chemistry of the material in the blow- off plume, to see if we're ablating through matrix or through bone," says Lowell Wood of Livermore. The laser is stopped as soon as phosphorus is detected, which is rare in ordinary rock but plentiful in mineralised bone. The researchers described the new technique at a meeting of the Society for Vertebrate Paleontology in Denver last month.

"It would be great for micropreparation of small things, such as tiny Mesozoic mammal skulls, and really good where it was difficult to distinguish the fossil from the matrix," Reser says. The Livermore researchers have only got as far as demonstrating that the system can tell the difference between bone and rock, but next year Wood hopes to put it to work preparing fossils. 
I'RI-VALLEY HERALD/OAKLAND TRIBUNE

November 11, 1999

T.ASERS MAY BARE BONES OF THE PAST

By Glear Roberts Jr.

LTERMORE - Sometimes separatiog fossils from rock is like finding the difference belween a rock and a hard place, paleontology experts say.

But Lawrence Llvermore Loboratory researchers are working on a pet project that uses lasers to zap nowy soil and rock while preserving the bones.

"You could remove material, a molecule at a time," said Pete Reser, chief preparator for the Now Mojico Muselus of Natural History. The method might allow "extretnoly delicate preparation (of fossils) that is not avallable at the moment."

Reser attended \& presentation on the lab researchers' proposied bone-elesaing method during the ansual intermational conference of the Society for Vertebrate Palcontology, held in Denver.

The ptocess would likely not be used for liberating a brontosaurus from its rocky tomb, he said, as it would be better sulted for freeing ting skeletons and bones from the grip of grit.

"This would be for tiny, thy things, "be stid, such as insect-eating creatures with jaws measuring fractions of an inch.

Rocks can surround or fuse with delicate bones, requiring careful handling and time-0onsuming labor.

The Iivermore Lab tochnique, still under developtonent, would fite quiek pulses from an infrared laser while uring sensors to identify the material that was blasted off the surface of the bone or skcleton.

Once tho equipmeat detects phosphorous - an element that is common in old bones - the laser pulses would cease, according to a Nov, 6 arricic in New Scientist magazine.

Lowell Wood, a Livermore Lab physicist, and other lab researchers who,are also pioneering the technology werc not available for comment Tuesday, said Llvermore Lab spokesman Gordon Yaxo.

Jobn Flyan, president of the Society for Vertebrate Raleomology, said that a 2-inch fossilized monkey skull could take one person a year to oleat completely, using comventional tochniques.

$X$-rays and other types of acans can belp resenrchers map tho fossils in a chunlr of recoverod soil and rook, and there are a rnge of mini-sandblasters and other equipment and chenicals to make the bones bare.

But sill there is room for advancerneat, Flynn said.

"There are a lot of eball goges. Techoigues that would enhance our ability to remove rock while not jeopardining the specimen would be great tools to have," Flynn said. 


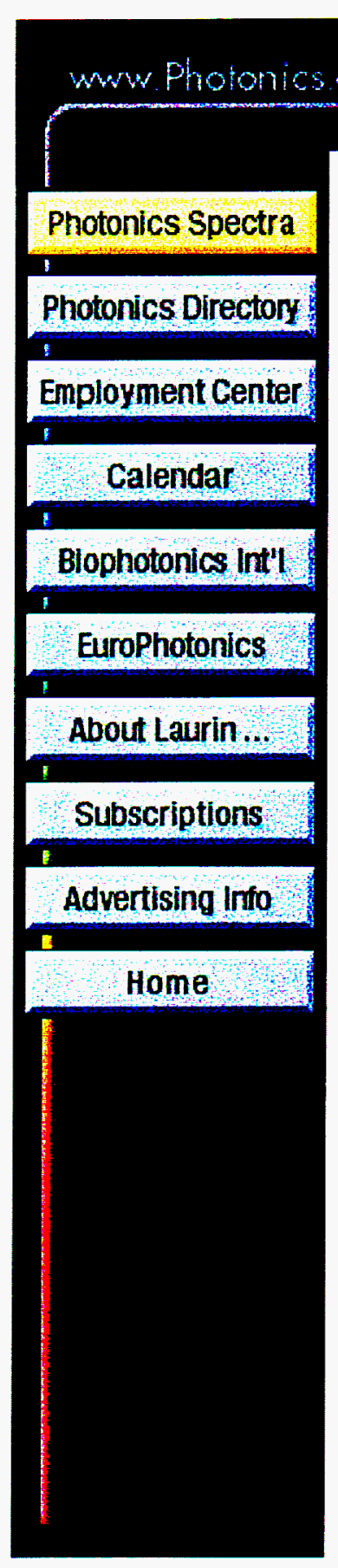

\section{Photonics Technology}

Tha Word beader in Ptrotorixs Fochnolagy since 1954

January 2000

Photonics Technology Pews:

Send News to: photonics@laurin.com

Sponsured by:

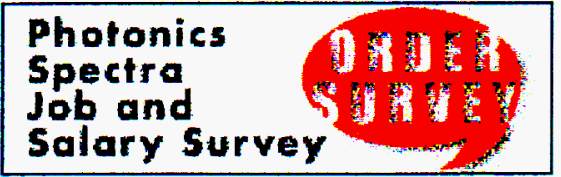

\section{Ultrafast Laser Frees Prehistoric Fossills}

LIVERMORE, Calif. -- A technique based on a scanning, ultrafast laser could soon prove invaluable to paleontologists attempting to liberate fossils entombed in surrounding rock.

Physicists from Lawrence Livermore National Laboratory, working on their own time, have refined a system that monitors the composition of the target and cuts power to the laser when it detects fossilized bone. The result could be a dramatic improvement over the current mechanical cleaning method used by paleontologists, which is both delicate and painstaking. It often takes months to prepare small fossils and years for entire dinosaurs.

The new method involves the use of a powerful, ultrafast laser emitting at $800 \mathrm{~nm}$ that is capable of producing a train of $10001-\mathrm{mJ}$ pulses per second. "The laser system being used is a homegrown one -- a 'kid brother' of the petawatt laser system first developed at Lawrence Livermore as part of the National Ignition Facility [program]," said Lowell Wood of Livermore.

Because the pulses are so short, the top layer of the target absorbs nearly all the energy, leaving those below unscathed. This permits the automated, raster-type scanning of a large surface to remove one $1-\mu \mathrm{m}$ layer after another as deep as may be desired.

\section{Emission spectrum}

The system determines the composition of the material by analyzing the emission spectrum of the vapor plume. To do this the researchers use optical spectrographic monitoring to observe the ablated material on the fly as well as to map the object in either two or three dimensions.

The laser switches off as soon as it detects phosphorus -- an element rare in ordinary rock but a primary component of fossilized bone. This sensitivity enables the user to preserve the fossil's surface structure to a degree previously impossible.

The team, which also includes Brent Stuart and Muriel Ishikawa of Lawrence Livermore, hopes to present several fossils prepared with the technique at next year's annual meeting of the international Society of Vertebrate Paleontology. Wood predicts that the method, with its high-speed and high-resolution pixel-by-pixel composition analyses, could find extensive commercial applications in the next 10 years, although specifics of other mainline applications are not publicly available. :

by Michad D. Wheter 